San Jose State University

SJSU ScholarWorks

Doctoral Projects

Master's Theses and Graduate Research

Spring 4-2017

\title{
Developing a Clinical Tool for the Assessment and Diagnosis of Pediatric Bipolar Disorder
}

Amanda Jill Horrocks

California State University, Northern California Consortium Doctor of Nursing Practice

Follow this and additional works at: https://scholarworks.sjsu.edu/etd_doctoral

Part of the Psychiatric and Mental Health Nursing Commons

\section{Recommended Citation}

Horrocks, Amanda Jill, "Developing a Clinical Tool for the Assessment and Diagnosis of Pediatric Bipolar Disorder" (2017). Doctoral Projects. 58.

DOI: https://doi.org/10.31979/etd.9ry3-6ynm

https://scholarworks.sjsu.edu/etd_doctoral/58

This Doctoral Project is brought to you for free and open access by the Master's Theses and Graduate Research at SJSU ScholarWorks. It has been accepted for inclusion in Doctoral Projects by an authorized administrator of SJSU ScholarWorks. For more information, please contact scholarworks@sjsu.edu. 


\begin{abstract}
Developing a Clinical Tool for the Assessment and Diagnosis of Pediatric Bipolar Disorder
\end{abstract}

Background: Pediatric bipolar disorder is a significant mental illness, characterized by changes in mood that can be abrupt, unpredictable, and extreme. The rate of diagnosis of this disorder has been increasing in recent decades. Purpose: A thorough review of existing literature was completed to inform practice. Additionally, a survey of clinician assessment practices was completed. Combining the information learned from the literature review, and the data from the clinician survey, a clinical tool has been created. This tool provides a thorough, multi-phasic process for the assessment and diagnosis of pediatric bipolar disorder. Method: Mental health clinicians were surveyed; respondents were obtained via snowball sampling. Chi square analysis was completed to determine the relationships between the assessment practices used and the level of licensure of the clinician, the length of time the clinician had been in practice, and the age range treated by the clinician. Results: No statistically significant results were identified from the Chi Square analyses. Inconsistency in the assessment strategies was noted, however. Implications/Conclusions: Further clinician data should be obtained due to the small sample size $(n=16)$. The resulting tool has been reviewed by a subject matter expert and will be validated in practice before diffusion.

Amanda Jill Horrocks, DNP(c), RN, PMHNP-BC

April 2017 

DEVELOPING A CLINICAL TOOL FOR THE ASSESSMENT AND DIAGNOSIS OF PEDIATRIC BIPOLAR DISORDER

by

Amanda Jill Horrocks, DNP(c), RN, PMHNP-BC

\author{
A project \\ submitted in partial \\ fulfillment of the requirements for the degree of \\ Doctor of Nursing Practice \\ California State University, Northern Consortium \\ Doctor of Nursing Practice
}

April 2017 


\section{APPROVED \\ For the California State University, Northern Consortium Doctor of Nursing Practice:}

We, the undersigned, certify that the project of the following student meets the required standards of scholarship, format, and style of the university and the student's graduate degree program for the awarding of the doctoral degree.

Amanda Jill Horrocks, DNP(c), RN, PMHNP-BC

Project Author

Ruth Rosenblum, DNP, RN, PNP-BC, CNS

Nursing

Chairperson's name (Chair) San Jose State University

Michael Terry, DNP, RN, FNP, PMHNP

Nursing

Committee member's name

University of San Diego 


\section{AUTHORIZATION FOR REPRODUCTION}

\section{OF DOCTORAL PROJECT}

$\underline{\mathrm{X}} \quad$ I grant permission for the reproduction of this project in part or in its entirety without further authorization from me, on the condition that the person or agency requesting reproduction absorbs the cost and provides proper acknowledgment of authorship.

Permission to reproduce this project in part or in its entirety must be obtained from me.

Signature of project author: Amanda Jill Horrocks, DNP(c), RN, PMHNP-BC 


\section{ACKNOWLEDGMENTS}

I would like to thank Dr. Ruth Rosenblum, Dr. Michael Terry, and Dr. Jason Earle for your support and guidance with this project. Your presence and input has been invaluable. Mom and Dad, thank you for your incessant support. Carter, Stuart, Gabriel, and Sebastian, you light up my life and bring me so much joy! Thank you to my family and friends who have stood by me, and encouraged me during this endeavor. AMDG + 
TABLE OF CONTENTS

Page

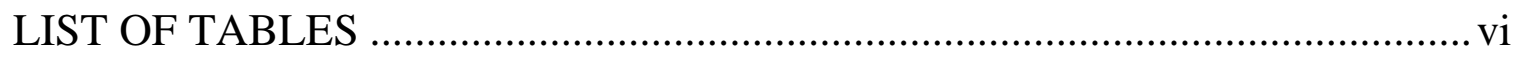

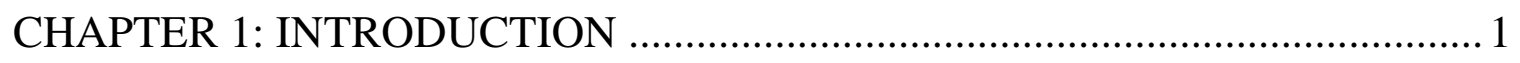

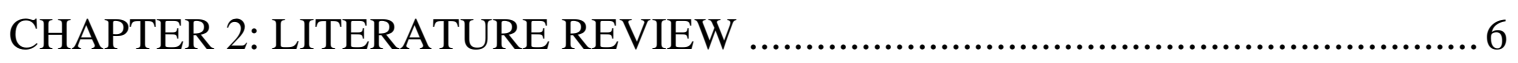

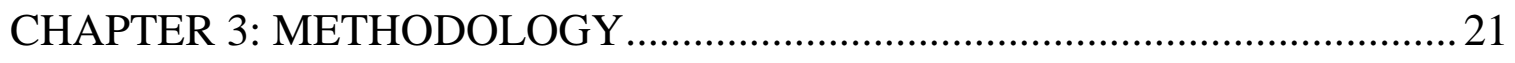

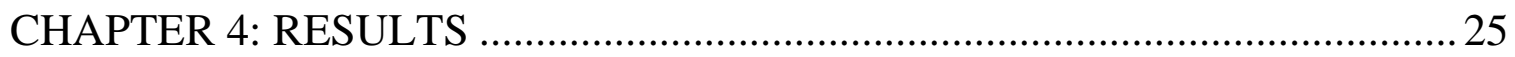

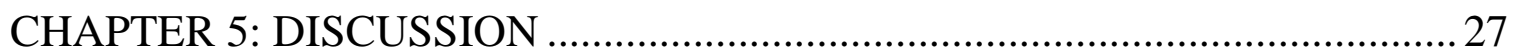

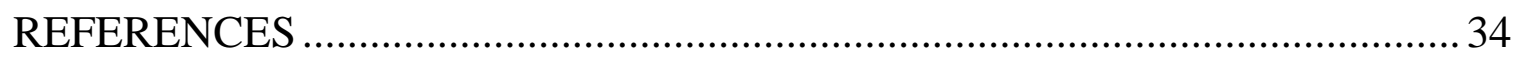

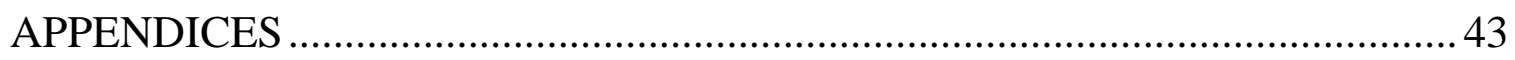

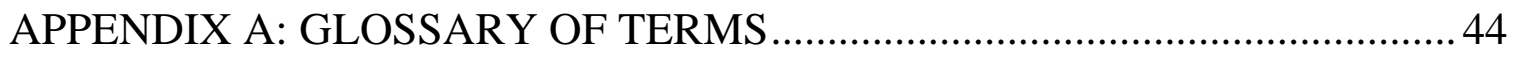

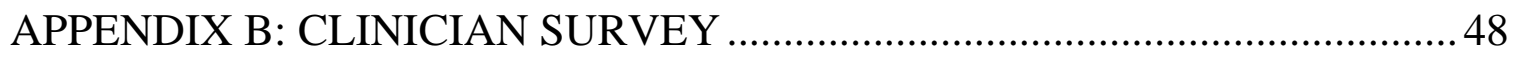

APPENDIX C: CLINICIAN DATA TABLES ………………............................55

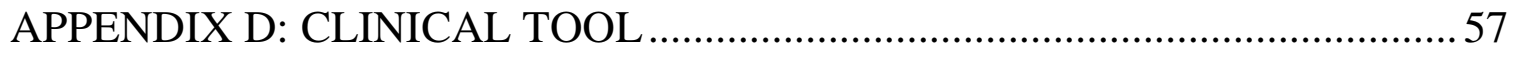

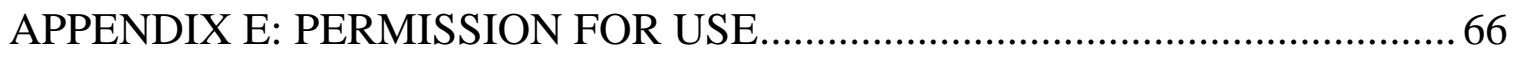




\section{LIST OF TABLES}

Page

Table 1. Assessment Strategies Employed..................................................56

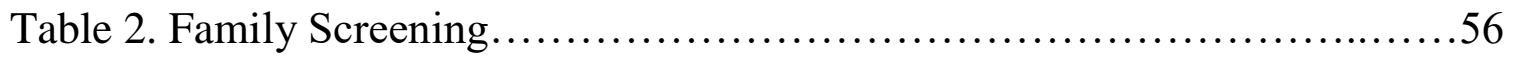





\section{CHAPTER 1: INTRODUCTION}

\section{Background}

Bipolar disorder (BPD) is a serious mental health condition characterized by recurrent periods of depression and elevated mood; these mood shifts are accompanied by cognitive and behavioral symptoms (Anderson, Haddad, \& Scott, 2012). Dilsaver (2011) reported an estimated lifetime incidence of bipolar spectrum disorders is between $4.4 \%$ and 6.4\%. Pediatric BPD is becoming more prevalent in the United States (US); in 1996 BPD was the least common diagnosis for children receiving inpatient psychiatric care, and by 2004 it was the most common (Littrell and Lyons, 2010). Contributing factors to this rise in diagnosis include an expansion of criteria to include a spectrum of BPD's, and a greater understanding of the genetic heritability of the condition (Littrell \& Lyons, 2010). The incidence rate of BPD in the pediatric population is approximately $2 \%$ (Youngstrom, Jenkins, Jensen-Doss, \& Youngstrom, 2012).

Across the lifespan, the implications of BPD are more significant than the other disorders that have similar clinical presentations, like attention deficit hyperactivity disorder (ADHD) or oppositional defiant disorder (ODD). Goldstein (2009) reported a lifetime rate of suicidal ideation of up to $75 \%$, a $44 \%$ suicide attempt rate, and a completed suicide rate of $25 \%$ for those with BPD. BPD is also known to be a kindling illness, making an accurate diagnosis and early treatment important (Weiss et al., 2015). Kindling refers to the phenomenon whereby the experience of life stress causes mood cycles to exacerbate in individuals suffering from conditions like BPD (Weiss, et al., 2015). 


\section{Purpose}

The purpose of this project was to complete a thorough review of existing literature about pediatric BPD, to conduct a survey amongst mental health clinicians, and use the information and data obtained from these processes, to create a clinical tool for the assessment and diagnosis of pediatric BPD. Literature has been reviewed to provide an evidence-based foundation for the development of the tool. Clinicians were queried and their responses analyzed to determine the level of licensure, the length of time in practice, age ranges treated, and assessment strategies employed. Research questions analyzed were:

1) Is there a significant difference between the type of licensure that a clinician holds and the assessment strategies used in clinical practice?

2) Is there a significant difference between the length of time a clinician has been in practice and the assessment strategies used in clinical practice?

3) Is there a difference between the age ranges that clinicians treat and the assessment strategies used in clinical practice?

Youngstrom, Jenkins, Jensen-Doss, and Youngstrom (2012) proposed several evidence-based steps that could be followed to assess pediatric BPD, but failed to incorporate a tool that could be used or medical screening elements. This project created a process that will incorporate clinical interviewing, obtaining collateral data, completing valid and reliable screening tools, and obtaining diagnostic studies before assigning this diagnosis. It is expected that the robust nature of the screening tool will allow for rapid adoption of the process by clinicians (Dearing, 2009). 
Current assessment practices to diagnose pediatric BPD are often subjective, inconsistent, and do not follow a cohesive, researched process (Jenkins, Youngstrom, Youngstrom, Feeny, \& Findling, 2011). Additionally, these authors noted that BPD, compared to other conditions, is more challenging to accurately diagnose due to the varying mood states in which a patient may present (Jenkins et al., 2011). A patient with Bipolar I disorder, for example, may present for treatment in full mania, hypomania, euthymia, dysthymia, severe depression, or a mixed state. Clinicians should conduct thorough interviews, and incorporate valid screening tools to assist in making a BPD diagnosis. It is also important to incorporate evidence-based, objective methods of assessment to reduce diagnostic ambiguity. Accurate, early identification and treatment will yield more positive patient outcomes due to the initiation of earlier treatment (Maniscalco \& Hamrin, 2008).

It is thought that in some situations pediatric BPD is over diagnosed, and in other scenarios, it is misdiagnosed as another condition (Danner et al., 2009). Several pediatric mental health conditions have overlapping symptoms (Youngstrom, Birmaher, \& Findling, 2008), and consequently, this makes accurate diagnosis challenging. Youngstrom et al. noted that irritable mood, distractibility, and pressured speech are common in pediatric BPD, but that these symptoms are not sensitive to the condition. Conduct disorder (CD), ODD, and ADHD all share symptoms in common with pediatric BPD, and they can be mistaken for each other clinically (Danner, et al., 2009).

Post et al., (2015) noted that there is a life expectancy loss of 13-30 years in individuals who have a serious mental illness. BPD is considered serious mental illness, according to DeHert et al., (2011). BPD is a costly public health issue, Dilsaver (2011) 
noted that the economic burden of bipolar I and bipolar II disorders is 151 billion dollars in the US annually. The significance of these statistics provides support for the diffusion of the clinical tool as an innovative clinical process. The degree to which the tool can help to change these statistics should be highlighted to increase the likelihood of adoption by clinicians. The tool represents an innovation to enhance current assessment strategies, and the diffusion of the attributes of the tool will aid clinicians in adopting the new process (Dearing, 2009).

\section{Theoretical Framework}

Diffusion of innovation theory provides a foundation and guide for the execution of this project. This theory involves taking the innovative idea of the clinical tool, and diffusing its content and use to clinicians, the clinicians choosing to accept the innovative process, and clinicians adopting the innovation into practice (Dearing, 2009). The beneficial attributes of the process must be readily identified by clinicians to aid in their ease of adoption. Information regarding the evidence-based assessment strategies incorporated, and rationale behind the recommendations for the innovative aspects of the tool will have to be diffused to clinicians to aid in their adoption process (Dearing, 2009). The theory suggests that accelerated diffusion of concepts, and thus accelerated adoption of the innovation can be achieved by incorporating validated concepts (Dearing, 2009). The clinical tool has achieved this by clustering together several evidence-based assessment strategies for the first several phases of assessment.

Murray (2009) discussed the application of the diffusion of innovation theory to psychotherapy practice. Murray reviewed the major tenets of the theory, and ultimately discussed that clinicians will more readily adopt the innovation into practice if they find 
the research meaningful to their clinical work (Murray, 2009). The clinical tool was developed with this in mind. Training and dissemination efforts will need to focus on ensuring clinicians can recognize the value of the new process, as well as its ease of use and adoption clinically. 


\section{CHAPTER 2: LITERATURE REVIEW}

\section{Assessment and Diagnosis}

Youngstrom, Jenkins, Jensen-Doss, and Youngstrom (2012) reviewed evidencebased assessment strategies used to diagnose pediatric BPD. The authors provided an algorithm of steps that could be used to assess for this condition, as well as a figure diagramming the use of these steps. There was no tool or manner in which the presented process should be applied in the clinical setting. Some similarities include the inclusion of several commonly utilized evidence-based assessment strategies. Some of the differences include that the authors of the article provided some steps in their process to use after a diagnosis of BPD had been assigned; the tool focuses on ruling in or ruling out the diagnosis. Another difference is that the created clinical tool includes recommendations for laboratory and imaging studies.

Algorta et al. (2013) completed a non-experimental, correlational study with a brief screening tool, the Family Index of Risk for Mood Issues (FIRM), to enhance the accuracy of pediatric BPD diagnoses. This study and resulting tool is aligned with one of the steps that is proposed by Youngstrom, Jenkins, Jensen-Doss, and Youngstrom (2012). It does not, however, give a comprehensive process for assessment, but provides a helpful tool for the clinician to use as a part of the process. The sample included pediatric subjects aged 5-18 years (average 10.3 years), and their caregivers. All subjects were seeking an outpatient psychiatric evaluation. Subjects came from 273 families, from these families, 43 youth were found to be on the bipolar spectrum. Caregivers completed the Mood Disorder Questionnaire - Parent (PMD-Q), and the FIRM appeared at the end of the PMD-Q. Caregivers also completed a Child Behavior Checklist (CBCL) about the 
youth subject. Youth subjects were assessed with the Kiddie Schedule for Affective Disorders and Schizophrenia - present and lifetime (K-SADS-PL), supplemented with other interview questions. Guardians were assessed for mental health history and were administered a Mini International Neuropsychiatric Interview (MINI). Logistic regression was completed to determine if FIRM provided a significant improvement in the identification of BPD. A $t$-test was also completed to establish if any test performed significantly better than another. The FIRM was more sensitive to BPD than other tools and did not correlate to ADHD. The logistic regression showed that FIRM provided a significant improvement in detecting BPD. An identified strength of this study was that the subjects were all assessed in a thorough manner by highly trained research assistants. An identified limitation of the study was that the demographic characteristics of the study, with $90 \%$ of subjects being from low-income families, likely reduced the effectiveness of the FIRM. This study is important to this project as it discussed the FIRM, which is an effective yet easily administered screening tool for the presence of BPD. The FIRM is included in the resulting tool of this clinical project for its ease of use and effectiveness.

Providing additional support to the previous two articles, Martelon, Wilens, Anderson, Morrison, and Wozniak (2012) completed a case-control family study to explore the link between challenges in the gestational and neonatal periods with the development of pediatric BPD. Subjects were obtained from two other ongoing similarly designed studies. There were 98 healthy controls, 120 bipolar patients, and 120 nonaffected siblings included. Subjects under the age of 18 were assessed using the K-SADS - epidemiologic version (K-SADS-E), and those 18 and older were assessed with the 
Structured Clinical Interview for DSM-IV (SCID). Mothers of all subjects completed a module of the Diagnostic Interview for Children and Adolescents - Parent Version (DICA-P). Statistical analyses included Chi square and $t$ tests. A significant relationship was found between BPD and neonatal challenges. No significant relationship was found between gestational challenges and the development of BPD. One limitation of this study is the fact that the DICA-P was completed retrospectively, and there is a chance that mothers may not accurately remember the significance of any challenges with their pregnancy or the neonatal period. This study is important to this project as it re-enforces the need to have a thorough gestational, neonatal, and pediatric history obtained during the clinical interview. Both Algorta et al. (2013) and Youngstrom, Jenkins, Jensen-Doss, and Youngstrom (2012) discussed the importance of understanding family history as a part of the assessment process.

Moving away from the process of assessment into the diagnosis itself, Hafeman et al. (2013) conducted a non-experimental, case-control study to determine if youth diagnosed with BPD, not otherwise specified (NOS) were similar to those with BPD I or BPD II. The sample included 707 children with a mean age of 9.4 years, presenting for treatment at an identified outpatient clinic. The subjects were evaluated and diagnosed with BPD I ( $n=71)$, BPD II ( $n=3)$, BPD NOS $(n=88)$, or no BPD $(n=545)$. Subjects were assessed using the K-SADS-PL, young mania rating scale (YMRS), K-SADS Depression Rating Scale, K-SADS Mania Rating Scale (KMRS), and the Children's Global Assessment Scale (CGAS). BPD II was eliminated from the analysis due to the low number of subjects with that diagnosis. Analysis of variance (ANOVA) testing was completed for continuous variables, and Chi square testing for the categorical variables, 
to determine differences between the three remaining groups. BPD NOS showed no significant difference from BPD I in mood symptoms at baseline. BPD NOS had lower KMRS than BPD I, but both had significantly elevated scores when compared to no BPD. CGAS also showed significant impairment in BPD NOS and BPD I compared to no BPD. An identified strength of this study was the thorough diagnostic assessment given to the subjects, including a myriad of validated assessment tools. This study is important to this project as it discussed the similarity in the clinical presentation for different diagnoses across the BPD spectrum.

Providing a different perspective, Benti, Manicavasagar, Proudfoot, and Parker (2014) conducted a qualitative study with a phenomenological approach to understand the early experiences of patients with BPD, and how they differed from those diagnosed with unipolar depression (UD). Some controversy still exists about diagnosing BPD in the pediatric population, and this study provided some information about individuals living with BPD. There were 39 participants aged 18-35 years old; all were diagnosed before age 24. Twenty participants had UD and 19 had BPD. All participants were given the MINI, YMRS, and the Hamilton Rating Sale for Depression (HAM-D) by the same clinician to determine that they were in a state of euthymia at the time of the study. After determining that they were eligible to participate based on diagnosis, age, and mood state, the participants completed a semi-structured interview. Descriptive statistics were obtained for the demographic data of participants. There was a trend noted for a younger age of onset in BPD than in UD. Indicators for BPD that were revealed included: adverse home environments, more assertive and disinhibited personalities, and mood swings at a young age. This study is important to the project as it gives insight to the age and nature 
of the onset of symptoms. This article provides support for the diagnosis and early treatment of BPD, based on the experiences of the subjects.

Similar to Benti, Manicavasagar, Proudfoot, and Parker (2014), Carpenter-Song (2009) completed a qualitative study with an ethnographic focus, to learn about the lived experience of patients and families dealing with mental health issues. One primary difference from the preceding article is that the previous study involved the patients recounting their earlier experiences, whereas Carpenter-Song studied pediatric patients and their families while they were still children. There were 20 families in the study: nine African American, ten Euro-American, and one Latino. The socioeconomic statuses of the families ranged from upper middle class to low income. Nineteen children in the study met criteria for BPD spectrum or ADHD. Youth were evaluated using the KSADS-PL to determine their diagnosis for the study. A semi-structured interview, the Subjective Experience of Illness and Medications in Youth was used to evaluate participants. Interviews were conducted in participant homes over multiple sessions. The study included detailed descriptions of three families and provided some of their responses to questions about their lived experience. The medicalization of these conditions was discussed, along with the participant's experiences with providers. An identified strength of this study is the ethnographic approach that is not taken into account in many quantitative studies. It is possible that families, like the described African American families in this study, would not participate in some other quantitative research because they do not attribute these mental health concerns to individual pathology. Having all perspectives considered and reported gives strength to this data and the study. This study is useful for this project as it discussed the lived experience of 
patients and families involved in the mental health system. Additionally, it discussed important cultural considerations regarding attitudes about mental illness that are important to consider. Families who do not believe in mental illness or sense stigma about seeking care might be less likely to seek help or discuss troubling symptoms.

\section{Neurobiological Changes}

Chang et al. (2005) conducted a case-control study to examine structures of the limbic system in patients with BPD and healthy controls. Twenty children and adolescents with BPD were recruited from an ongoing study. Each of the subjects had a gender, age, and IQ-matched control recruited from the community. SCID, K-SADS, and K-SADS-PL were used to evaluate subjects. Bipolar patients were additionally evaluated with the YMRS. T-tests were used to analyze the data obtained from magnetic resonance imaging (MRI) studies. No statistical significance was seen between BPD subjects and controls for total brain volume, thalamus, caudate, and hippocampus. Total amygdalar volume, as well as right and left amygdalar volume was significantly decreased in the BPD subjects. Further study showed this reduction to be related to depletion of gray matter volume (GMV) in the right amygdala. Treatment with lithium or valproic acid was shown to be somewhat protective of this change. This study provides support for this project in that it demonstrates underlying neurobiological processes that appear to be a part of the BPD presentation. It also supports that treatment of BPD can be protective against this neurobiological change; an important consideration when considering diagnosing BPD in the pediatric population.

Similar to Chang et al. (2005), Lisy et al. (2011) conducted a study that found changes in GMV in MRI scans of patients with BPD. Additionally, both studies had 
findings showing that treatment with certain medications for BPD is brain protective. Lisy et al. completed a longitudinal case-control study to assess changes in GMV in subjects with BPD and healthy controls. Fifty-eight subjects with BPD and 48 healthy controls underwent a baseline MRI scan, and then a follow-up scan some months later (mean of 11months). Assessments were completed using the K-SADS and the SCID based on the age of the subject. BPD patients were in a variety of mood states at the time of their baseline MRI. Healthy controls were found to have greater gray matter volume compared to BPD patients overall. BPD patients, however, had increased gray matter volume over time. There was a positive correlation in the bipolar group between the length of time between scans and the change in gray matter volume. BPD patients receiving antipsychotics or anticonvulsants showed increases in the left frontal gyrus and the left medial gyrus, respectively. This study did not note a change in GMV between scans in patients receiving lithium. The longitudinal nature of this study is a strength. One limitation of this study is that subjects with nicotine dependence were not excluded from participation, and this has been linked to GMV changes in the past. This study is important to the project as it demonstrated neurostructural changes related to BPD.

Different from the preceding two studies, Xiao et al. (2013) conducted a casecontrol study to determine neurologic changes of manic pediatric BPD patients. Lisy et al. (2011) included patients in a variety of mood states, whereas Xiao et al. included only manic patients. The study by Xiao et al. included 15 patients aged 12 to 17 years old from outpatient psychiatric clinics in China, and they were age and sex matched with healthy controls. Subjects met criteria for BPD, had to have one previous manic or hypomanic episode, and were manic at the time of completing the study. Participants 
were evaluated using the K-SADS-PL, and the Wechsler Abbreviated Scale for intelligence. BPD patients additionally completed the YMRS. Statistical analysis was completed using Chi square tests and $t$ tests. MRI scans were completed, and changes were found in the bilateral hippocampus, right anterior cingulate cortex, right parahippocampal gyrus, and left caudate. Chang et al. (2005) did not find changes in the caudate or hippocampal structures like this study did. Some of this could be related to differences in study design. This study demonstrated neurobiological changes that can be observed during the resting state, and during task completion in BPD. This study is important to the project as it outlines some of the neurobiological changes that can be appreciated in the brain of the bipolar patient compared to a healthy control when there was no task being completed. This information suggests that objective findings might be possible when diagnosing pediatric BPD.

Exploring a different aspect of neurobiological function in BPD, Quiroz, Gray, Kato, and Manji (2008) completed a retrospective review to examine the role of mitochondrial function in BPD. The authors noted evidence is emerging that mitochondria play a role in the ability for neurotransmitters to freely move between neurons. Dysfunction in calcium transportation and utilization is another anomaly that has been documented in BPD; this could also be linked to mitochondrial function. Over 12,000 hippocampal genes from autopsied brains of patients with BPD, schizophrenia, and healthy controls were analyzed. Forty-three genes were expressed in a diminished manner for BPD as opposed to schizophrenia. Forty two percent of these changes were related to mitochondrial function. It was noted that treatment with lithium and valproic acid were protective to brain function, similar to the other studies discussed that 
completed MRI scans. This article is important to the project as it explored the biologic basis for BPD.

\section{Susceptibility Genes and Genetic Linkage}

Lichtenstein et al. (2009) conducted a population-based retrospective study to assess heritability and environmental factors that contribute to susceptibility for schizophrenia, BPD, or a comorbidity of both conditions. The sample was obtained by linking national registries. Over nine million potential participants were identified, and the article stated that over 2 million families were analyzed. Rates of disease in family members was compared to those with hospitalizations who were the same age and gender. Different family types were analyzed in an attempt to separate genetic from environmental factors for susceptibility. A generalized multivariate mixed linear model was used. Heritability of schizophrenia was estimated to be $64 \%$, and BPD was estimated to be 59\%. An identified limitation was that the data used to determine the sample was the lack of information about the diagnostic practices of the treating clinicians. Additionally, they may not utilize a standardized approach to the assessment of BPD and did not know that their assigned diagnoses would be used for the purpose of this study. This study supports this project as it demonstrated the high rate of heritability of BPD, warranting consideration of the genetic factors during the assessment of potential BPD cases.

Different from Lichtenstein et al. (2009), Barden et al. (2006) completed a casecontrol study to examine three different specific genes as potential factors leaving one susceptible to developing BPD. The genes studied were: purinergic receptor P2X 7 (P2RX7), purinergic receptor P2X 4 (P2RX4), and calcium/calmodulin dependent protein 
kinase kinase 2 (CAMKK2). Two hundred thirteen individuals from Quebec were identified using the French version of SCID. There were 214 control subjects. Blood samples were obtained from all subjects. Fisher's exact tests were used to analyze data. Single nucleotide polymorphism's (SNP) associated with P2RX7 accounted for 56\% of all SNP's in this genetic area. All three genes studied are implicated in the synaptic use of calcium and subsequent modulation of neurotransmitters. The data obtained from this study suggest susceptibility to BPD may exist through P2RX7 and CAMKK2, though stronger in the former. There was a significant association between 2 markers of P2RX7 in BPD as compared to control subjects. The authors also suggested that due to the space between implicated susceptibility genes, there may be a gene cluster associated with BPD. This study is important to this project as it gives discussion to the biological basis of BPD, and offers some genetic markers that may be implicated in the development of BPD.

Doyle et al. (2010), explored genetic susceptibility to BPD, and like Barden et al. (2006), found some genes suggestive of playing a role in the development of the disorder. Doyle et al. additionally explored the heritability of BPD. The authors completed a nonexperimental, correlational descriptive study to expand on previous research regarding the diagnosis and genetic basis of pediatric BPD. Subjects were obtained from a group previously studied in a sibling-pair linkage ADHD project. Subjects aged 6-17 years old were assessed using the K-SADS-E, and subjects 18 years old and older were assessed with the SCID. Weschler Intelligence Scales (IQ) were completed for all subjects as well. A CBCL was completed by guardians of subjects aged 6 to 18 years. Genotyping was then completed on the subjects. Youth with CBCL data were the focus on of the 
main analysis. The independent variable was the youth with the juvenile BPD phenotype based on the CBCL scores (CBCL-JBD). Heritability for CBCL-JBD was found. The genomic scans revealed suggestive linkage for youth with CBCL-JBD at 1p21.1 (changes with chromosome 1), 6p21.3 (changes with chromosome 6), and 8q21.13 (changes with chromosome 8), though no genetic markers had a statistically significant correlation to the phenotype. An identified limitation of this study was that only 54\% of CBCL were returned. This study is important to the project because it discussed the heritability of BPD, and found some suggestive susceptibility genes, though statistical significance was not found.

Another exploration of genetic susceptibility for BPD was completed by Jang et al. (2015), who completed an animal study on transient receptor potential cation channel subfamily M member 2 (TRPM2) deficient mice, to explore the biologic basis of BPD in humans. Many behavioral tasks were completed and video recorded. Mice also underwent electroencephalogram studies and blood tests. Animal handling protocols were followed, and this study was completed in Korea. One way ANOVA tests were used to analyze data obtained. This study examined the changes associated with three mutations of TRPM2. One particular mutation, D543E demonstrated significant changes in behavior and function. Having these mutations leads to an inappropriate production of other proteins naturally occurring in the brain. One of these, GSK-3, is known to be directly related to mood regulation. The nature of this study being an animal study with interwoven knowledge of human BPD is both a strength and weakness. The strength lies in the intricate and robust study that was completed, but the weakness is that this has not been replicated fully in the human population. This study is important to this project by 
providing information that could be directly related to the development of BPD in humans.

Olivera et al. (2014) explored the genetic factors related to BPD development from a different perspective. The authors conducted a non-experimental, case-control study to determine if there was a genetic response to infection or inflammation that leaves one susceptible to the development of BPD. DNA from 571 French patients with BPD (229 early onset before age 22, and 342 late onset), and 199 healthy controls were analyzed for toll-like receptor 2 (TLR2) polymorphisms. All subjects were euthymic at the time of inclusion, as evidenced by completion of a Montgomery-Asberg Depression Rating Scale and a Mania Rating Scale. The independent variable was the presence of BPD, and the dependent variables were the presence or absence of TLR2 polymorphisms. Genotype frequencies between the early onset, late onset, and healthy controls were performed using Chi square tests. The TLR2 rs380499 TT and TLR2 rs4696480 TT genotypes were found to be significantly more present in early onset BPD patients than late onset. No statistically significant difference was found between the late onset group and the healthy controls. An identified strength of this study was the homogenous sample and a large number of sample subjects. This study is relevant to the project as it provides information regarding background questions that should be asked during the clinical interview, and identified statistically significant susceptibility genes for pediatric BPD.

Deepening the body of evidence for genetic linkage, Shifman et al. (2004) conducted a case-control study to explore the association between catechol-Omethyltransferase (COMT) and BPD. This study was completed in Jerusalem, Israel. 
There were 217 unrelated case subjects; diagnosis was confirmed with the SCID. All subjects were of Ashkenazi Jewish descent. Control samples were obtained from around 1,050 healthy Ashkenazi individuals. Chi square tests were completed to analyze data received. Gender specific samples were run, as a gender effect had previously been identified with COMT. A significant association was found between SNP's of COMT and BPD. Based on previous research, the data of this study also demonstrated a relationship between schizophrenia and BPD. The size of the control group is a strength of this study. However, the study does not indicate if these controls were screened. Some controls may have had BPD and did not know it. Though the strength of the correlation between COMT and BPD has been found to be more modest in the decade since this research was completed, this article provides support for the completion of this project due to the relationship found with both BPD and schizophrenia.

Like other studies in this section, Zhou et al. (2009) completed a study to explore another potential gene leaving individuals susceptible to developing BPD. Zhou et al. conducted a study that had a correlational component for European Caucasian families, and a case-control component for Chinese subjects. The study was conducted to determine if there was a link between Sp4 transcription factor (Sp4) and BPD, as Sp4 is known to play a role in hippocampal development in animal studies. Ten SNP's located across Sp4 were evaluated. RMANOVA tests were used to analyze the data obtained. 4 SNP's were found to be statistically significant and associated with BPD. The number of subjects and the fact that results were replicated in two different ethnic groups are strengths of this study. The article is important for the project because it identifies a 
susceptibility gene that was found to be statistically significant in a large sample across ethnic groups.

\section{Gaps in Research}

Literature searches were completed in the CINAHL and PsycINFO databases using the search terms "assessment diagnosis pediatric bipolar disorder," "assessment pediatric bipolar disorder," and "pediatric bipolar disorder." Additionally, a search was completed in both CINAHL and PsycINFO for "susceptibility genes bipolar disorder," as there is interest in incorporating emerging information regarding genetic polymorphisms that are related to BPD into this project. Youngstrom, Birmaher, and Findling (2008) reviewed the sensitivity and specificity of symptoms to BPD and other conditions. Studies referenced in the literature review often utilized validated rating scales as a part of the assessment strategy. This is helpful but does not seem substantial enough, as diagnostic challenges still exist. Rucklidge (2008) found that retrospective completion of rating scale tools did not reveal prodromal periods for those patients who were diagnosed after puberty. They did demonstrate symptoms that were indicative of psychopathology, however. This re-enforces the need for thorough assessment during the childhood and adolescent years so that treatment onset is not delayed. Kessing, Vradi, and Andersen (2015) noted that of those diagnosed with pediatric BPD, $40.7 \%$ of patients received the diagnosis at their first point of contact, but $24 \%$ of these patients eventually were given a different diagnosis after follow up.

Faraone, Glatt, and Tsuang (2003) noted that pediatric BPD is often more severe, and may be under stronger genetic influence than adult onset BPD. Several genes have been identified as leaving one susceptible to developing pediatric BPD. One of these 
genes was discussed in the article by Olivera et al. (2014) in the literature review above. Some of the others include specific polymorphisms of COMT, brain-derived neurotrophic factor (BDNF), and the dopamine transporter (DAT) (Mick et al., 2008). Many of these genetic pathways show susceptibility, but none of them provide a direct pathway to diagnosis based on the current information available. Given the information available, and considering that no one tool provides a completely reliable pathway to diagnosis, this project is needed to provide as consistent and clear a path as possible to diagnosis. 


\section{CHAPTER 3: METHODOLOGY}

\section{Study Design and Research Questions}

The project had several elements: a systematic review of the literature to inform practice, a survey of clinicians, and the development of a clinical tool that could be implemented to more thoroughly and consistently assess for pediatric BPD. Research questions analyzed were:

1) Is there a significant difference between the type of licensure that a clinician holds and the assessment strategies used in clinical practice?

2) Is there a significant difference between the length of time a clinician has been in practice and the assessment strategies used in clinical practice?

3) Is there a difference between the age ranges that clinicians treat and the assessment strategies used in clinical practice?

\section{Sampling and Method}

Survey respondents were recruited via snowball sampling; approximately 50-100 respondents were desired to minimize distribution errors in responses (Field, 2013). Criteria for inclusion required that the respondent be a medical doctor, physician's assistant, nurse practitioner, or clinical nurse specialist working in the field of mental health. Clinicians additionally needed to treat some children or adolescents in their practice to be included in the survey. Children and adolescents, for this project, were defined as people aged 3 to 17 years. Clinicians did not have to exclusively treat this age group and did not need to have any specific portion of their practice be dedicated to the child and adolescent population. Exclusion criteria are any individuals who did not meet the aforementioned practice criteria. All subjects were able to provide their informed 
consent to participate in the survey, and none belonged to a protected category of subjects. Several published studies explore aspects of the existence, assessment, and diagnosis of pediatric BPD, but there does not appear to be any published English literature other than Youngstrom, Jenkins, Jensen-Doss, and Youngstrom (2012) that address a process for assessment. The similarities and differences between their article and this work were previously explored in this paper.

Respondent participation was voluntary. The respondents received the link for the survey from people that they know, due to the snowball sampling methodology. The potential respondent had the sole ability to click the link and begin the survey process. No investigational, experimental, or special procedures were used in the completion of the project. Each respondent should have only completed the survey once, as addressed in the informed consent, and the location of completion was up to the respondent. The survey could have been completed on any computer or mobile device that could access the survey website.

\section{Data Collection}

The survey (Appendix B) was created via the Survey Monkey platform, and covered six areas: informed consent to participate, the age range treated by the clinician, the type of licensure of the clinician, the length of time the clinician had been in practice, what strategies they used to assess for pediatric BPD, and whether they felt a standardized assessment process would assist them in the assessment and diagnosis of pediatric BPD. Survey items contained primarily check box answers, and it was estimated that unless a clinician chose to write in free text, survey completion took about five to ten minutes. Institutional Review Board approval from California State University, Fresno was 
obtained. Data was collected from September 13, 2016, through October 12, 2016. No standardized instruments were used for data collection in this project.

\section{Data Analysis}

Emphasis was placed on the descriptive statistics generated from the data received. This provided information about current practice strategies employed by clinicians, which substantiated the need for the development of the clinical tool. Three groupings of variables were subject to statistical analysis. Chi square analysis was performed on: the age range treated by the clinician and what assessment strategies employed in practice, length of time in practice and assessment strategies employed in practice, and level of licensure and assessment strategies employed in practice (Field, 2013a). None of the Chi square analyses resulted in significant findings. However, the survey data yielded varied assessment and interview strategies (Appendix C).

\section{Potential Benefits}

There were no immediate or direct benefits to any respondent who completed the survey. Any respondent who wishes to receive results of the survey data was provided information to request this as a part of the informed consent. It was anticipated that clinicians were likely to see more benefit from the resulting tool that was created, than from participation in the survey. This tool will guide clinicians through a robust assessment of possible pediatric BPD, and aid them in more accurately diagnosing this condition.

\section{Potential Risks}

Risks to respondents were minimal for this study. Risks involved the time needed to complete the survey and any distress that occurred from examining their assessment 
strategies. There were no social, physical, economic, or legal risks anticipated for any survey respondent. The clinical tool will be validated as a separate endeavor after completion of this project and academic program, so there was no risk at this time to any patient. There were no violations of normal expectations.

\section{Precautions to Minimize Risk}

Completion of the survey was voluntary and anonymous. At no point during the survey was any personally identifying information gathered. The respondents completed the survey in an electronic format. There were no individual survey tools collected by any other means, and therefore no physical storage or destruction was necessary. Survey data is accessed by the investigator on the survey website. This website is username and password protected, preventing any unauthorized access to survey data. Any physical data that is printed, and not maintained in an electronic form on the secured website, will be secured in a locked filing cabinet. Data analysis reports from statistical software are being stored in a biometrically locked laptop computer. 


\section{CHAPTER 4: RESULTS}

Data from the clinician survey was analyzed using IBM SPSS, version 23. Descriptive statistics, and frequencies were obtained in addition to completion of analysis related to the research questions. Review of the literature yielded information related to the assessment of pediatric BPD, susceptibility genes related to BPD, and the neurobiological changes seen in BPD. The information from the literature review, and data from the clinical survey were combined to guide the development of the clinical tool.

\section{Results}

Sixteen respondents completed the required questions of the survey. Twenty respondents began the survey; four either did not complete the required questions of the survey or did not meet inclusion criteria. The sample was comprised of physicians $(\mathrm{n}=4$, $25 \%)$, nurse practitioners $(\mathrm{n}=11,68.8 \%)$, and a clinical nurse specialist $(\mathrm{n}=1,6.2 \%)$. Half of these clinicians treated patients across the lifespan $(n=8,50 \%)$, while some treated child and adolescents only ( $\mathrm{n}=6,37.5 \%)$, and the remainder treated children, adolescents, and young adults ( $\mathrm{n}=2,12.5 \%)$. The length of time these clinicians had been in practice was also explored. The largest group of respondents had been in practice between six and ten years $(n=7,43.8 \%)$. Other responses included: zero to five years $(n=2,12.5 \%)$, eleven to twenty years $(n=3,18.7 \%)$, and twenty-one or more years $(n=4,25 \%)$.

\section{Chi Square Analyses}

Testing of the aforementioned research questions was completed by performing Chi square analyses to determine if there were any significant relationships between the assessment strategies used by clinicians and 1) the level 
of licensure of the clinician (mood journaling $\mathrm{p}=0.055$, sleep journaling $\mathrm{p}=0.113$, rating scales $\mathrm{p}=0.379$, lab studies $\mathrm{p}=0.195$, will not diagnose $\mathrm{p}=0.660$ ), 2 ) the length of time the clinician had been in practice (mood journaling $\mathrm{p}=0.454$, sleep journaling $\mathrm{p}=0.917$, rating scales $\mathrm{p}=0.450$, lab studies $\mathrm{p}=0.468$, will not diagnose $\mathrm{p}=0.558$ ), and 3 ) the age range the clinician treated (mood journaling $\mathrm{p}=0.558$, sleep journaling $\mathrm{p}=0.141$, rating scales $\mathrm{p}=0.915$, lab studies $\mathrm{p}=0.641$, will not diagnose $\mathrm{p}=0.180$ ). None of the Chi square analyses resulted in significant findings. None of the clinician respondents reported using imaging studies or genetic testing regularly, so there are no $\mathrm{p}$ values for these measures. The weakness of the sample size may have contributed to the lack of significance in findings. This should be considered, and more data obtained in the future. 


\section{CHAPTER 5: DISCUSSION}

\section{Discussion Regarding Assessment Strategies}

Overall, clinicians demonstrated consistency in their responses regarding the symptoms assessed when diagnosing pediatric BPD. Though no statistically significant findings were found between the assessment strategies used and the clinician survey data, there was variation seen in the responses to the assessment strategies employed in practice (see Appendix C, Chart 1). The variation in responses is either random or related to a variable that was not studied. It is presumed that use of the clinical tool will help to create greater consistency in the assessment strategies used. The final question of the survey asked respondents whether or not a valid and reliable assessment tool would be helpful to them, the majority of respondents ( $n=14,87.5 \%$ ) indicated that this would be helpful to them. Based on this data obtained from the clinician study, there should be openness to the diffusion of the tool and adoption of its process.

Data obtained regarding the family of origin showed some variation in responses as well (see Appendix C, Chart 2), though not as dramatically as the assessment strategies. A thorough family history should be consistently obtained due to the heritability of BPD (Lichtenstein et al., 2009). The significance of these particular aspects of family history are important in the assessment of pediatric BPD, further consistency in this area of assessment could yield more effective diagnostics. Sleep disturbance is a common symptom of BPD. Exploring patterns of this occurring in the family of origin can be helpful in identifying BPD in the patient; this response showed the greatest variation in responses in this section of questions. 
Clinicians were given the opportunity to provide free text responses regarding how they distinguish between the aforementioned conditions that have similar symptoms to pediatric BPD. The common themes contained in the responses received for this question ( $\mathrm{n}=10$ ) included assessing for sleep disturbances, manic or grandiose periods, and thorough assessment. One clinician responded that they would refer out any child or adolescent that they suspected had BPD. Another free text question asked clinicians to explain their perspective if they would not diagnose BPD in a child or adolescent. Two clinicians created responses for this question, and both indicated that the clinician would diagnose BPD in an adolescent if they met diagnostic criteria, but would not diagnose BPD in a child. This question also did not require a response of the respondents.

\section{Project Outcomes}

A clinical tool has been created (see Appendix D) to aid in the assessment and diagnosis of pediatric BPD. This tool has been created by synthesizing the data obtained through the clinician survey, the information obtained during the literature review, and the clinical knowledge of the author. The clinical tool is designed to be used in the mental health setting, and could also be used in the primary care setting as a means of determining when to refer for specialty assessment.

The clinical tool provides a comprehensive checklist of symptoms and prompts the clinician to have the patient to mood journal. After this, the tool guides the clinician to have the patient or their family to complete rating scales. Though any reliable and validated screening tool is acceptable, information regarding the FIRM (Algorta et al., 2013), and the Child Mania Rating Scale - Parent Version (CMRS-P) (Pavuluri, Henry, Devineni, Carbray, \& Birmaher, 2006) are included. Permission exists for the FIRM in 
academic and research contexts. The CMRS-P is available for download on the internet, and permission for use was separately obtained by the author (Appendix E). If pediatric BPD is still suspected, further evaluation is recommended. Laboratory studies are recommended to rule out any underlying medical comorbidities that may contribute to the clinical presentation; these would also allow for baseline levels to be obtained should pharmacologic management commence in the future. Though the laboratory tests ordered should be based upon the assessment of the clinician, some routine recommendations to consider are: complete blood count with differential, comprehensive metabolic panel, lipid panel, glycosylated hemoglobin, and thyroid stimulating hormone. Other tests that may be warranted based on the individual patient presentation might include: urine drug screen, urine human chorionic gonadotropin, prolactin, and vitamin D. Testing for methylenetetrahydrofolate reductase (MTHFR) polymorphisms should be considered on a case by case basis, as MTHFR polymorphisms are associated with mood struggles, although this is not diagnostic of BPD (Gilbody, Lewis, \& Lightfoot, 2007). It is possible that with this level of thorough assessment, BPD could be ruled in or out. However, if the clinical picture remains uncertain, MRI studies should be considered to assess for neurobiological changes. Current research suggests that changes can be found in the scans of BPD patients; particular consistency has been noted in changes in GMV (James et al., 2011).

Validation of this screening tool will be completed in the future. After validity and reliability have been established, broader dissemination, publication, and training regarding the use of the tool will occur. It is hoped that the use of this tool will provide a standardized platform for the assessment and diagnosis of BPD, and help to create greater 
diagnostic accuracy. It is anticipated that the tool will be available initially in pen and paper format, and eventually developed into a smartphone application. Use of this tool will provide an innovative approach to assessment, that will enhance the efficiency and effectiveness of assessment. These attributes of the tool will be addressed during training to aid in diffusion and adoption of the tool concepts.

\section{Limitations}

Crede (2010) reported the effects of random responding to the validity of psychological tests and in research. The author noted that random responding could lead to erroneous correlational relationships being identified. The converse could also be true, that relationships that would have appeared stronger had the responses not been random will not be identified. It is unknown if the effects of random sampling contributed to the results of this project, further research is needed.

A low response rate from clinicians was another limitation of this project. Cunningham, et al. (2015) noted that physicians are typically low responders to survey research. The authors conducted survey research of various types of physicians to look at response rates. Psychiatrists had by far the lowest return rate, and this was with a supported, advertised, and structured dissemination of the survey (Cunningham et al., 2015).

A perceived bias of this project could be that the clinician survey was disseminated to many professional contacts of the author. However, these contacts allowed the survey to reach several large university medical centers, several university systems, the Ministry of Health in Singapore, several psychiatric hospitals, and a large medical group. Additionally, a past president of the Northern California Regional 
Organization of Child and Adolescent Psychiatry was able to disseminate the survey to clinician members. Unfortunately, despite these seeming far-reaching contacts, very few surveys were completed.

\section{Recommendations for Further Study}

Mental health providers like psychologists, therapists, and social workers can diagnose pediatric BPD. These clinicians cannot order imaging studies or laboratory studies, however, and as such, they were not included in this initial clinician survey. They should be included in any future clinician surveys to understand their assessment strategies, and to help garner more robust data. Due to the low number of clinician respondents, continued study of clinician practices would be useful to see if any statistical significance could be obtained and to re-enforce the findings that were discovered.

The most recent edition of the Diagnostic and Statistical Manual of Mental Disorders (DSM-5) brought updates to many pediatric mental health conditions. The DSM-5 provides support for the diagnosis of pediatric BPD when the appropriate symptomatology exists (American Psychiatric Association, 2013). One diagnostic addition to the DSM-5 was that of disruptive mood dysregulation disorder (DMDD) (American Psychiatric Association, 2013). This diagnosis captures many of the children and adolescents that might have previously been mislabeled as having BPD. This is considered a depressive disorder, however, not a cycling mood disorder like BPD. Irritability in children and adolescents is a hallmark feature of both conditions. However, a distinguishing factor is that the irritability in DMDD is persistently irritable, and in BPD there will be periods of irritability followed by other distinguishable mood states (American Psychiatric Association, 2013). Stringaris et al. (2010) noted that youth with 
severe mood dysregulation, as is seen in DMDD are very unlikely to develop a mixed or manic episode. This type of episode would be seen relatively commonly in the BPD population. Additionally, neurobiological differences can be appreciated in the brains of patients with severe mood dysregulation, like DMDD, as compared to those with BPD, when given the same tasks to complete (Adleman et al., 2011).

Ensuring that the clinical tool is sensitive to BPD is important. This will help reduce misdiagnosis of other similarly presenting conditions like DMDD, ODD, CD, and ADHD. This consideration is one reason that the FIRM was selected as one of the recommended screening methods within the clinical tool. Research has shown that the FIRM was more sensitive to BPD than other available scales, and was not sensitive to ADHD (Algorta et al., 2013). The clinical tool now needs to be validated before disseminating it into clinical practice. This is a crucial next research step to allow this project to proceed.

\section{Healthcare Improvement}

Creating consistency in the evaluation of pediatric BPD will help to ensure that the disorder is more accurately diagnosed. A more robust evaluation process will likely help parents of potential BPD patients to be more accepting of the diagnosis, and thereby help ensure early treatment. Early identification and treatment will help lead to more positive outcomes for this vulnerable population (Maniscalco \& Hamrin, 2008). The intent is for this clinical tool to reach beyond psychiatry, and into primary care as well. The assessment strategies will be clearly defined enough that those working in primary care would be comfortable completing the assessment, and referring for treatment if a diagnosis of BPD is likely. 


\section{Conclusion}

The development of the clinical tool provides a model for assessment that can be used to diagnose BPD in the pediatric population. Data shows that the incidence of the pediatric BPD has been rising (Littrell \& Lyons, 2010). Current literature has demonstrated that there is evidence for biological and genetic changes that can be seen in the BPD patient, and the incorporation of the expanding field of science into diagnostic practices is warranted. Clinician survey data demonstrated that while clinicians seem to be consistent in their assessment of symptoms of BPD, there is inconsistency in the use of other screening strategies. Ultimately, the majority of clinician respondents indicated that a valid and reliable clinical tool would be helpful to them professionally. This project seeks to provide such a tool, and it is hoped that broad diffusion and adoption of this tool will help to improve the care and outcomes of child and adolescent patients everywhere. 
REFERENCES 


\section{REFERENCES}

Adleman, N. E., Kayser, R., Dickstein, D., Blair, R. J., Pine, D., \& Leibenluft, E. (2011). Neural correlates of reversal learning in severe mood dysregulation and pediatric bipolar disorder. Journal of the American Academy of Child \& Adolescent Psychiatry, 50(11), 1173-1185.

Algorta, G. P., Youngstrom, E. A., Phelps, J., Jenkins, M. M., Youngstrom, J. K., \& Findling, R. L. (2013). An inexpensive family index of risk for mood issues improves identification of pediatric bipolar disorder. Psychological Assessment, 25(1), 12-22. doi:10.1037/a0029225

American Psychiatric Association. (2013). Diagnostic and Statistical Manual of Mental Disorders (5th ed.). Arlington, VA: American Psychiatric Association.

Anderson, I. A., Haddad, P. M., \& Scott, J. (2012). Bipolar disorder. British Medical Journal, 345(7889), 1-10. doi:10.1136/bmj.e8508

Barden, N., Harvey, M., Gagne, B., Shink, E., Tremblay, M., Raymond, C.,...Muller-Myshok, B. (2006). Analysis of single nucleotide polymorphisms in genes in the chromosome 12Q24.31 region point to P2RX7 as a susceptibility gene to bipolar affective disorder. American Journal of Medical Genetics Part B, 141B, 374-382.

doi:10.1002/ajmg.b.30303

Benti, L., Manicavasagar, V., Proudfoot, J., \& Parker, G. (2014). Identifying early indicators in bipolar disorder: A qualitative study. Psychiatric Quarterly, 85, 143-153. 
Carpenter-Song, E. (2009). Caught in the psychiatric net: Meanings and experiences of ADHD, pediatric bipolar disorder and mental health treatment among a diverse group of families in the United States. Culture, Medicine, and Psychiatry, 33, 61-85. doi:10.1007/s11013-008-9120-4

Chang, K., Karchemskiy, A., Barnea-Goraly, N., Garrett, A., Simeonova, D. I., \& Reiss, A. (2005). Reduced amygdalar gray matter volume in familial pediatric bipolar disorder. Journal of the American Academy of Child \& Adolescent Psychiatry, 44(6), 565-573. doi:10.1097/01.chi.0000159948.75136.0d

Crede, M. (2010). Random responding as a threat to the validity of effect sized estimates in correlational research. Educational and Psychological Measurement, 70(4), 596-612.

Cunningham, C., Quan, H., Hemmelgarn, B., Noseworthy, T., Beck, C., \& Dixon, E.,...Jette, N. (2015). Exploring physician specialist response rates to webbased surveys. BMC Medical Research Methodology, 15(1), 32-39.

Danner, S., Fristad, M. A., Arnold, L. E., Youngstrom, E. A., Birmaher, B., Horwitz, S. M.,...Kowatch, R. A. (2009). Early-onset bipolar spectrum disorders: Diagnostic issues. Clinical Child and Family Psychology Review, 12, 271-293. doi:10.1007/s10567-009-0055-2

Dearing, J. W. (2009). Applying diffusion of innovation theory to intervention development. Research on Social Work Practice, 19(5), 503-518. 
DeHert, M., Correll, J. B., Cetkovich-Bakmas, M., Cohen, D., Asai, I., Detraux, J.,...Leucht, S. (2011). Physical illness in patients with severe mental disorders. I. Prevalence, impact of medications and disparities in health care. World Psychiatry, 10, 52-77.

Dilsaver, S. C. (2011). An estimate of the minimum economic burden of bipolar I and II disorders in the United States: 2009. Journal of Affective Disorders, 129, 79-83. doi:10.1016/j.jad.2010.08.030

Doyle, A. E., Biederman, J., Ferreira, M. A., Wong, P., Smoller, J W., \& Faraone, S. V. (2010). Suggestive linkage of the child behavior checklist juvenile bipolar disorder phenotype to 1p21, 6p21, and 8q21. Journal of the American Academy of Child \& Adolescent Psychiatry, 49(4), 378-387. doi:10.1016/j.jac.2010.01.008

Faraone, S. V., Glatt, S. J., \& Tsuang, M. T. (2003). The genetics of pediatriconset bipolar disorder. Biological Psychiatry, 53, 970-977. doi:10.1016/S0006-3223(02)01893-0

Field, A. (2013). Everything you never wanted to know about statistics. In Discovering statistics using IBM SPSS statistics (4th ed.pp. 40-88). Los Angeles, CA: Sage.

Field, A. (2013a). Comparing several means: ANOVA (GLM 1). In Discovering statistics using IBM SPSS statistics (4th ed.pp. 429-477). Los Angeles, CA: Sage. 
Gilbody, S., Lewis, S., \& Lightfoot, T. (2007). Methylenetetrahydrofolate reductase (MTHFR) genetic polymorphisms and psychiatric disorders: A HuGE review. American Journal of Epidemiology, 165(1), 1-13. doi:10.1093/aje/kwj347

Goldstein, T. R. (2009). Suicidality in pediatric bipolar disorder. Child and Adolescent Psychiatric Clinics of North America, 18, 339-352. doi:10.1016/j.chc.2008.11.005

Hafeman, D., Axelson, D., Demeter, C., Findling, R., Fristad, M. A., Kowatch, R. A.,...Birmaher, B. (2013). Phenomenology of bipolar disorder not otherwise specified in youth: A comparison of clinical characteristics across the spectrum of manic symptoms. Bipolar Disorders, 15, 240-252. doi:10.1111/bdi.1054

James, A., Hough, M., James, S., Burge, L., Winmill, L., Nijhawan, S.,...Zarei, M. (2011). Structural brain and neuropsychometric changes associated with pediatric bipolar disorder with psychosis. Bipolar Disorders, 13, 16-27. doi:10.1111/j.1399-5618.2011.00891.x

Jang, Y., Lee, S. H., Lee, B., Jung, S., Khalid, A., Uchida, K.,...Oh, U. (2015). TRPM2, a susceptibility gene for bipolar disorder, regulates glycogen synthase kinase-3 activity in the brain. The Journal of Neuroscience, 35(34), 11811-11823. doi:10.1523/JNEUROSCI.5251-14.2015 
Jenkins, M. M., Youngstrom, E. A., Youngstrom, J. K., Feeny, N. C., \& Findling, R. L. (2011). Generalizability of evidence-based assessment recommendations for pediatric bipolar disorder. Psychological Assessment, 24(2), 269-281. doi:10.1037/a0025775

Kessing, L. V., Vradi, E., \& Andersen, P. K. (2015). Diagnostic stability in pediatric bipolar disorder. Journal of Affective Disorders, 172, 417-421. doi:10.1016/j/jad.2014.10.037

Lichtenstein, P., Yip, B. H., Bjork, C., Pawitan, Y., Cannon, T. D., Sullivan, P. F., \& Hultman, C. M. (2009). Common genetic determinants of schizophrenia and bipolar disorder in Swedish families: A population based study. The Lancet, 373, 234-239.

Lisy, M. E., Karvis, K. B., DelBello, M. P., Mills, N. P., Weber, W. A., Fleck, D.,...Adler, C. M. (2011). Progressive neurostructural changes in adolescent and adult patients with bipolar disorder. Bipolar Disorders, 13, 396-405. doi:10.1111/j.1399-5618.2011.00927

Littrell, J., \& Lyons, P. (2010). Pediatric bipolar disorder: Part I - is it related to classical bipolar. Children and Youth Services Review, 32, 945-964. doi:10.1016/j.childyouth.2010.03.020

Maniscalco, E. R., \& Hamrin, V. (2008). Assessment and diagnostic issues in pediatric bipolar disorder. Archives of Psychiatric Nursing, 22(6), 344-355. doi:10.1016/j.apnu.2007.08.006 
Martelon, M. K., Wilens, T. E., Anderson, J. P., Morrison, N. R., \& Wozniak, J. (2012). Are obstetrical, perinatal, and infantile difficulties associated with pediatric bipolar disorder? Bipolar Disorders, 14, 507-514. doi:10.1111/j.1399-5618.2012.01027.x

Mick, E., Kim, J. W., Biederman, J., Wozniak, J., Wilens, T., Spencer, T.,...Faraone, S. V. (2008). Family based association study of pediatric bipolar disorder and the dopamine transporter gene (SLC6A3). American Journal of Medical Genetics Part B, 147B, 1182-1185. doi:10.1002/ajmg.b.30745

Murray, C. E. (2009). Diffusion of innovation theory: A bridge for the researchpractice gap in counseling. Journal of Counseling \& Development, 87, 108116.

Olivera, J., Hamdani, N., Busson, M., Etain, B., Bennabi, M., Amokrane, J.,...Tamouza, R. (2014). Association between toll-like receptor 2 gene diversity and early-onset bipolar disorder. Journal of Affective Disorders, 165, 135-141. doi:10.1016/j.jad.2014.04.059

Pavuluri, M. N., Henry, D. B., Devineni, B., Carbray, J. A., \& Birmaher, B. (2006). Child mania rating scale: Development, reliability, and validity. Journal of the American Academy of Child \& Adolescent Psychiatry, 45(5), 550-560. 
Post, R. M., Altshuler, L., Leverich, G. S., Frye, M. A., Suppes, T., McElroy, S. L.,...Rowe, M. (2015). Relationship of clinical course of illness variables to medical comorbidities in 900 adult outpatients with bipolar disorder. Comprehensive Psychiatry, 56, 21-28. doi:10.1016/j.comppsych.2014.08.050

Quiroz, J. A., Gray, N. A., Kato, T., \& Manji, H. K. (2008). Mitochondrially mediated plasticity in the pathophysiology and treatment of bipolar disorder. Neuropsychopharmacology, 33, 2551-2565. doi:10.1038/sj.npp.1301671

Rucklidge, J. J. (2008). Retrospective parent report of psychiatric histories: Do checklists reveal specific prodromal indicators for postpubertal-onset pediatric bipolar disorder? Bipolar Disorders, 10, 56-66.

Shifman, S., Bronstein, M., Sternfeld, M., Pisante, A., Weizman, A., Reznik, I.,...Darvasi, A. (2004). COMT: A common susceptibility gene in bipolar disorder and schizophrenia. American Journal of Medical Genetics Part B, 128B, 61-64. doi:10.1002/ajmg.b.30032

Stringaris, A., Baroni, A., Haimm, C., Brotman, M., Lowe, C. H., Myers, F.,...Leibenluft, E. (2010). Pediatric bipolar disorder versus severe mood dysregulation: Risk for manic episodes on follow-up. Journal of the American Academy of Child \& Adolescent Psychiatry, 49(4), 397-405.

Weiss, R. B., Stange, J. P., Boland, E. M., Black, S. K., LaBelle, D. R., Abramson, L. Y., \& Alloy, L. B. (2015). Kindling of life stress in bipolar disorder: Comparison of sensitization and autonomy models. Journal of Abnormal Psychiatry, 124(1), 4-16. doi:10.1037/abn0000014 
Xiao, Q., Zhong, Y., Lu, D., Gao, W., Jiao, Q., Lu, G., \& Su, L. (2013). Altered regional homogeneity in pediatric bipolar disorder during manic state: A resting-state fMRI study. PLoS One, 8(3), 1-9. doi:10.1371/journal.pone.0057978

Youngstrom, E. A., Birmaher, B., \& Findling, R. L. (2008). Pediatric bipolar disorder: Validity, phenomenology, and recommendations for diagnosis. Bipolar Disorders, 10, 194-214. doi:10.1111/j.1399-5618.2007.00563.x

Youngstrom, E. A., Jenkins, M. M., Jensen-Doss, A., \& Youngstrom, K. Y. (2012). Evidence-Based assessment strategies for pediatric bipolar disorder. The Israel Journal of Psychiatry and Related Sciences, 49(1), 15-27.

Zhou, X., Tang, W., Greenwood, T. A., Guo, S., He, L., Geyer, M. A., \& Kelsoe, J. R. (2009). Transcription factor SP4 is a susceptibility gene for bipolar disorder. PLoS One, 4(4), 1-11. doi:10.1371/journal.pone.0005196 
APPENDICES 


\section{APPENDIX A: GLOSSARY OF TERMS}




\begin{tabular}{|l|l|}
\hline Term & Abbreviation \\
\hline Analysis of Variance & ANOVA \\
\hline Attetion Deficit Hyperactivity Disorder & ADHD \\
\hline Bipolar Disorder & BPD \\
\hline Brain-derived Neurotrophic Factor & BDNF \\
\hline Calcium/Calmodulin Dependent Protein Kinase Kinase 2 & CAMKK2 \\
\hline Catechol-O-Methyltransferase & COMT \\
\hline Child Behavior Checklist & CBCL \\
\hline Child Mania Rating Scale - Parent Version & CMRS-P \\
\hline Family Index of Risk for Mood Disorders & FIRM \\
\hline Children's Global Assessment Scale & CGAS \\
\hline Conduct Disorder & CD \\
\hline Diagnostic Interview for Children and Adolescents - Parent & DICA-P \\
\hline Dersion & DAT \\
\hline Disruptive Mood Dysregulation Disorder & \\
\hline Dopd Statistical Manual of Mental Disorders, 5 th & DMDD \\
\hline & \\
\hline
\end{tabular}




\begin{tabular}{|l|l|}
\hline Gray Matter Volume & GMV \\
\hline Hamilton Rating Scale for Depression & HAM-D \\
\hline Kiddie Schedule for Affective Disorders and Schizophrenia & K-SADS \\
\hline $\begin{array}{l}\text { Kiddie Schedule for Affective Disorders and Schizophrenia } \\
\text { - Epidemiologic }\end{array}$ & K-SADS-E \\
\hline $\begin{array}{l}\text { Kiddie Schedule for Affective Disorders and Schizophrenia } \\
\text { - Mania Rating Scale }\end{array}$ & KMRS \\
\hline $\begin{array}{l}\text { Kiddie Schedule for Affective Disorders and Schizophrenia } \\
\text { - Present and Lifetime }\end{array}$ & K-SADS-PL \\
\hline & MRI \\
\hline Magnetic Resonance Imaging & MTHFR \\
\hline Methylenetetrahydrofolate Reductase & TLR2 \\
\hline Toll-like Receptor 2 & MINI \\
\hline Mini International Neuropsychiatric Interview & PMD-Q \\
\hline & SDD \\
\hline Mood Disorder Questionnaire - Parent & SCID \\
\hline Oppositional Defiant Disorder & \\
\hline Purinergic Receptor P2X 4 & \\
\hline & \\
\hline & \\
\hline
\end{tabular}




\begin{tabular}{|l|l|}
\hline Transient Receptor Potential Cation Channel Subfamily M & TRPM2 \\
Member 2 & \\
\hline Unipolar Depression & UD \\
\hline & YMRS \\
\hline
\end{tabular}


APPENDIX B: CLINICIAN SURVEY 


\title{
Appendix B - Clinician Survey
}

\author{
Informed Consent
}

* 1. You are invited to participate in a survey conducted by Amanda Horrocks, NP, of the California State University, Northern California Consortium, Doctor of Nursing Practice Program. I hope to learn what assessment strategies are being used by clinicians to diagnose pediatric bipolar disorder. You were selected as a possible participant in this study because you are a medical doctor, nurse practitioner, physician's assistant, or clinical nurse specialist practicing in mental health.

If you decide to participate, I will ask you to complete a brief survey regarding your practice style, once. This survey is designed to take 10 minutes or less to complete. This survey is anonymous, and there is little risk, other than the potential discomfort caused by taking the time to document your assessment strategies. There is no direct benefit to you, at this time, for completing this survey. It is hoped that indirect benefit will be achieved in the future by the creation of a practice tool that could be used clinically. The purpose of this survey is to gather information, only. If you would like to be sent study results when completed, please email me at the email address below.

Any information that is obtained in connection with this survey is anonymous, and will not be identified to you in any way. Aggregate data will be used to identify trends in practice and statistical significance, as a part of a larger project.

Your decision whether or not to participate will not prejudice your future relations with California State University, Northern California Consortium, Doctor of Nursing Practice Program. If you decide to participate, you are free to withdraw your consent and to discontinue participation at any time without penalty. The Committee on the Protection of Human Subjects at California State University, Fresno has reviewed and approved the present research.

If you have any questions, please ask. If you have any additional questions later, Amanda Horrocks, NP, (amazinggrace426@mail.fresnostate.edu) will be happy to answer them. Questions regarding the rights of research subjects may be directed to Constance Jones, Chair, CSUF Committee on the Protection of Human Subjects, (559) 278-4468.

If you would like a copy of this consent, please print it from your browser. If you are unable to do so, please email me at the email address above, and a copy will be provided to you.

YOU ARE MAKING A DECISION WHETHER OR NOT TO PARTICIPATE. SELECTING "I AGREE" INDICATES THAT YOU HAVE DECIDED TO PARTICIPATE, HAVING READ THE INFORMATION PROVIDED ABOVE.

\section{IAGREE}

I DO NOT AGREE 


\section{Age Range}

* 2. What age range do you treat in your practice? For this survey, "children and adolescents" are defined as people aged 3-17 years old.

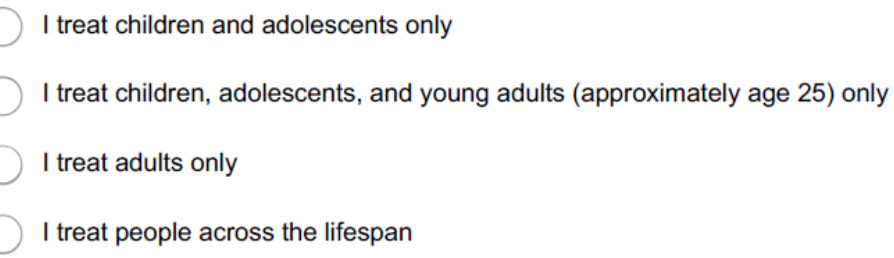

\section{Licensure Held}

* 3. What licensure do you hold? Please selectonly one if you have more than one of these.

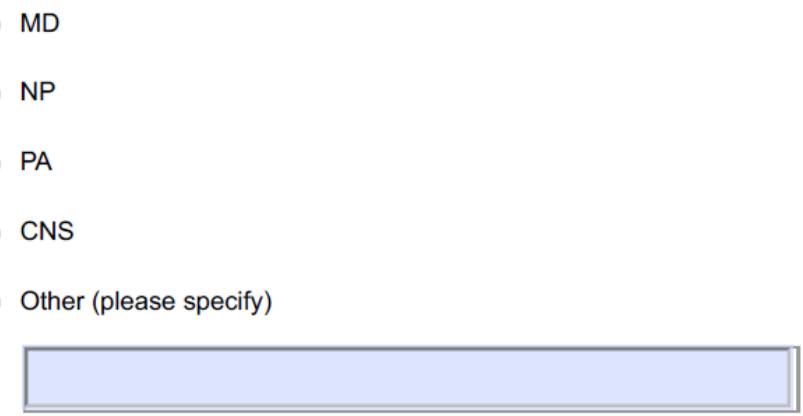

\section{Length of Time in Practice}

* 4. How long have you been practicing in the field of mental health?
$0-5$ years
$6-10$ years
$11-20$ years
21 or more years 


\section{Assessment Strategies}

* 5. How often do you inquire about each of the following symptoms (current or historical) in your assessment of bipolar disorder in children and adolescents?

\begin{tabular}{|c|c|c|c|c|}
\hline & $\begin{array}{l}\text { Most of the time (greater } \\
\text { than or equal to } 75 \% \text { of } \\
\text { the time) }\end{array}$ & $\begin{array}{l}\text { Occasionally } \\
\text { (approximately } 26-74 \% \text { of } \\
\text { the time) }\end{array}$ & $\begin{array}{l}\text { Rarely (approximately } 1- \\
25 \% \text { of the time) }\end{array}$ & Never \\
\hline \multicolumn{5}{|l|}{$\begin{array}{l}\text { Trouble focusing or } \\
\text { distractibility }\end{array}$} \\
\hline \multicolumn{5}{|l|}{$\begin{array}{l}\text { Difficulty with tracking } \\
\text { details }\end{array}$} \\
\hline Depression symptoms & O & C & 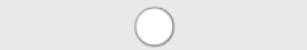 & \\
\hline \multicolumn{5}{|l|}{$\begin{array}{l}\text { Abnormal excitement or } \\
\text { excess energy }\end{array}$} \\
\hline Problems at school & & & & \\
\hline \multicolumn{5}{|l|}{ Frequent mood swings } \\
\hline \multicolumn{5}{|l|}{$\begin{array}{l}\text { Unexplained mood } \\
\text { elevation }\end{array}$} \\
\hline \multicolumn{5}{|l|}{ Hypersexuality } \\
\hline Substance abuse & & & D & \\
\hline \multicolumn{5}{|l|}{ Legal history } \\
\hline Unexplained irritability & & & & \\
\hline \multicolumn{5}{|l|}{ Temper outbursts } \\
\hline \multicolumn{5}{|l|}{ Sleep disturbance } \\
\hline \multicolumn{5}{|l|}{$\begin{array}{l}\text { Rapid or pressured } \\
\text { speech }\end{array}$} \\
\hline \multicolumn{5}{|l|}{ Racing thoughts } \\
\hline \multicolumn{5}{|l|}{$\begin{array}{l}\text { Difficulty maintaining } \\
\text { boundaries }\end{array}$} \\
\hline \multicolumn{5}{|l|}{$\begin{array}{l}\text { Short term memory } \\
\text { issues }\end{array}$} \\
\hline \multicolumn{5}{|l|}{ Impulsivity } \\
\hline \multicolumn{5}{|l|}{ Bedwetting } \\
\hline \multicolumn{5}{|l|}{ Extreme anxiety or panic } \\
\hline $\begin{array}{l}\text { Suicidal/Homicidal } \\
\text { ideation, plan, or intent }\end{array}$ & & & & \\
\hline
\end{tabular}




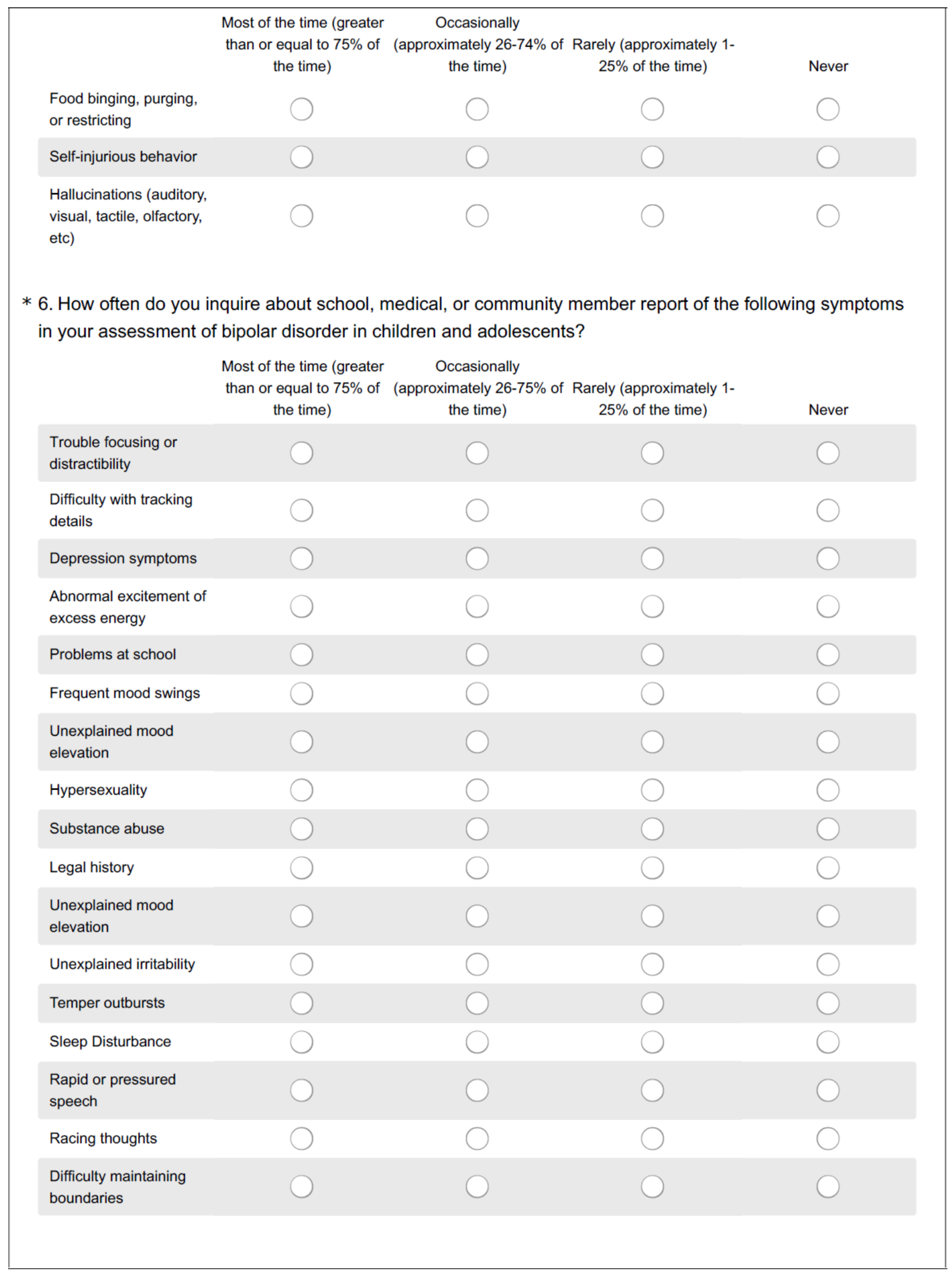




$\begin{gathered}\text { Most of the time (greater } \\ \text { than or equal to } 75 \% \text { of } \\ \text { the time) }\end{gathered}$
(approximately 26-75\% of Rarely (approximately 1 -
the time)
issues

* 7. How often do you inquire about family history of the following in your assessment of bipolar disorder in children and adolescents?

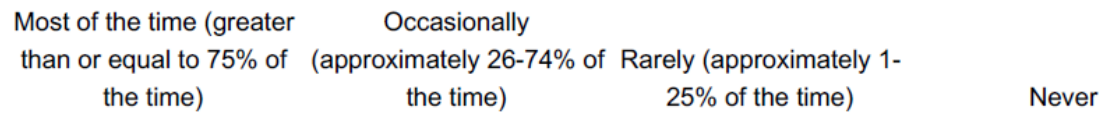

Any substance abuse in immediate or extended family members?

Any insomnia concerns in immediate or extended family members?

Any history of completed or attempted suicide in immediate or extended family members? 


\section{Assessment Strategies}

* 8. What assessment strategies do you use on a regular basis (greater than or equal to $75 \%$ of the time) to diagnose bipolar disorder in children and adolescents? Please check all that apply.

$\square$ Mood journaling

Sleep journaling

Rating scales such as CBCL, CBQ, K-SADS, or FIRM

$\square$ Imaging studies

$\square$ Laboratory tests

$\square$ Genetic testing

I I will not diagnose bipolar disorder in this population

Other (please specify)

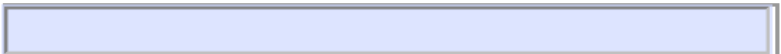

9. If you do not diagnose bipolar disorder in children and adolescents, please explain why.

10. How do you distinguish bipolar disorder from ADHD, ODD, CD, DMDD, and substance abuse?

* 11. Would a valid and reliable standardized assessment algorithm assist you in diagnosing bipolar disorder in the child and adolescent population?

Yes

No

Thank you!

Thank you for taking the time to complete this survey. Your contribution toward this project is greatly appreciated! 
APPENDIX C: CLINICIAN DATA TABLES 


\section{Appendix C - Clinician Data Charts}

\section{Chart 1 - Assessment Strategies Employed}

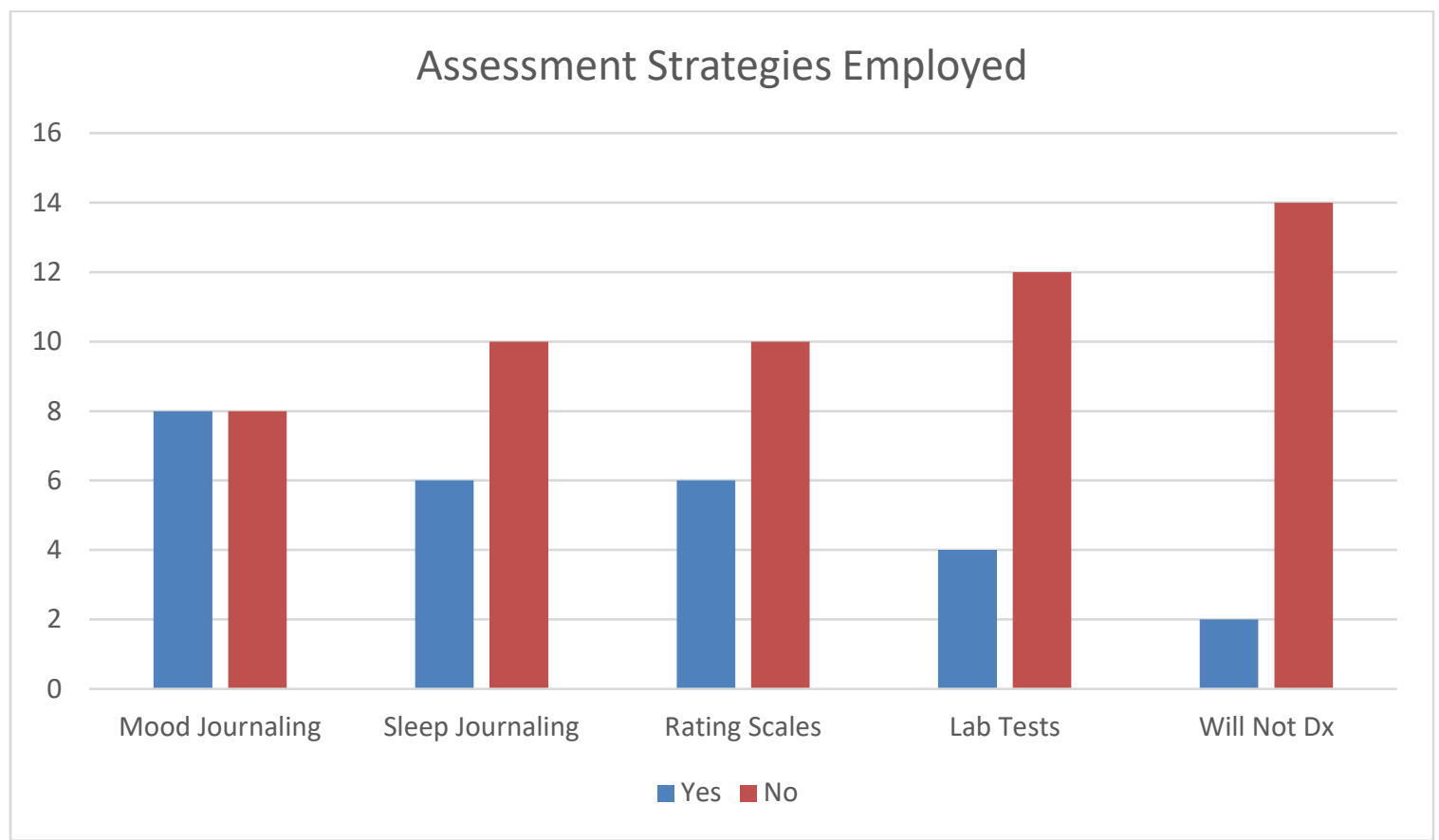

Chart 2 - Family Screening

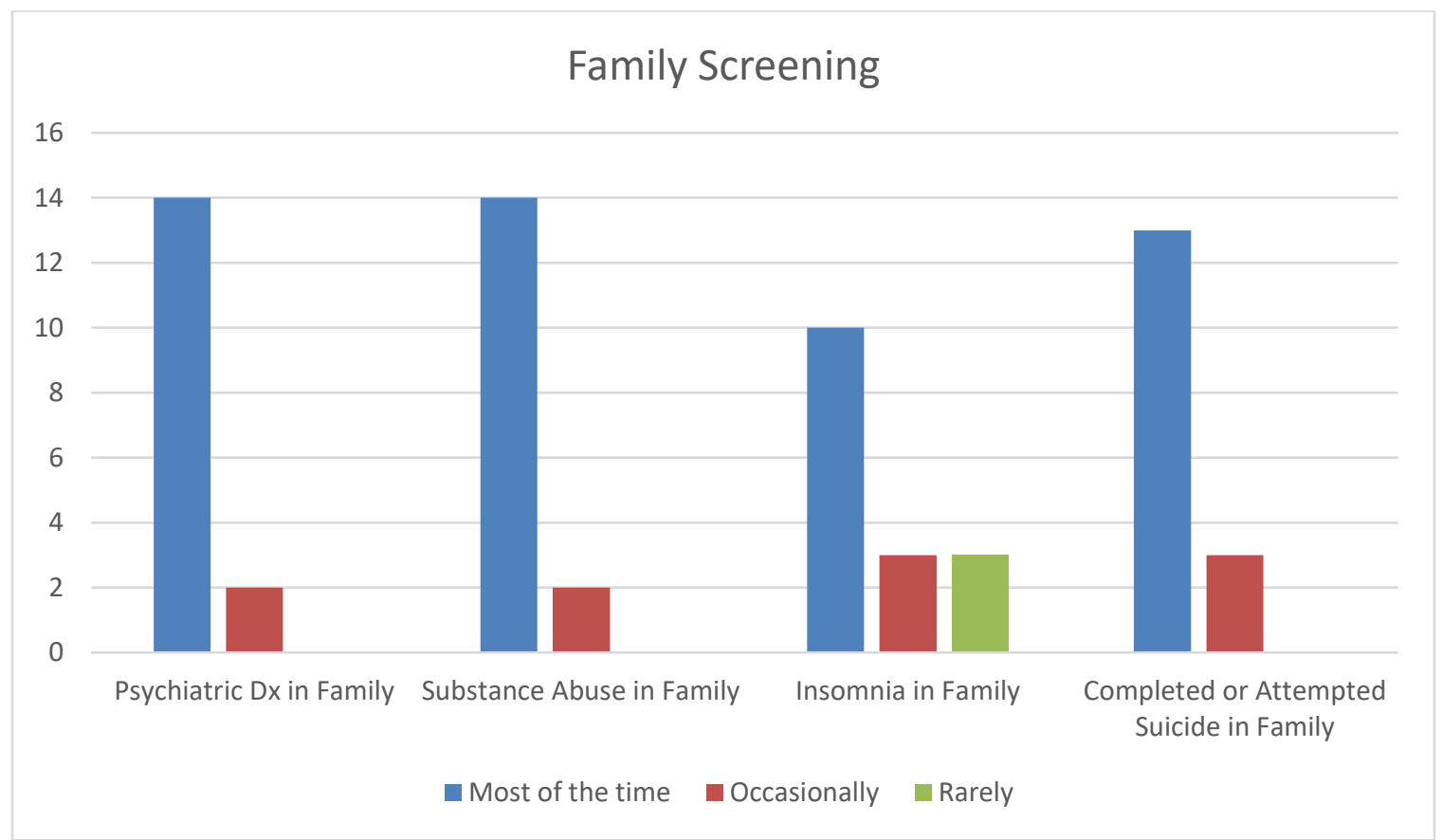


APPENDIX D: CLINICAL TOOL 
Appendix D - Clinical Tool

Clinical Tool for the Assessment and Diagnosis of Pediatric Bipolar Disorder

Developed by Amanda Horrocks, DNP(c), RN, PMHNP-BC

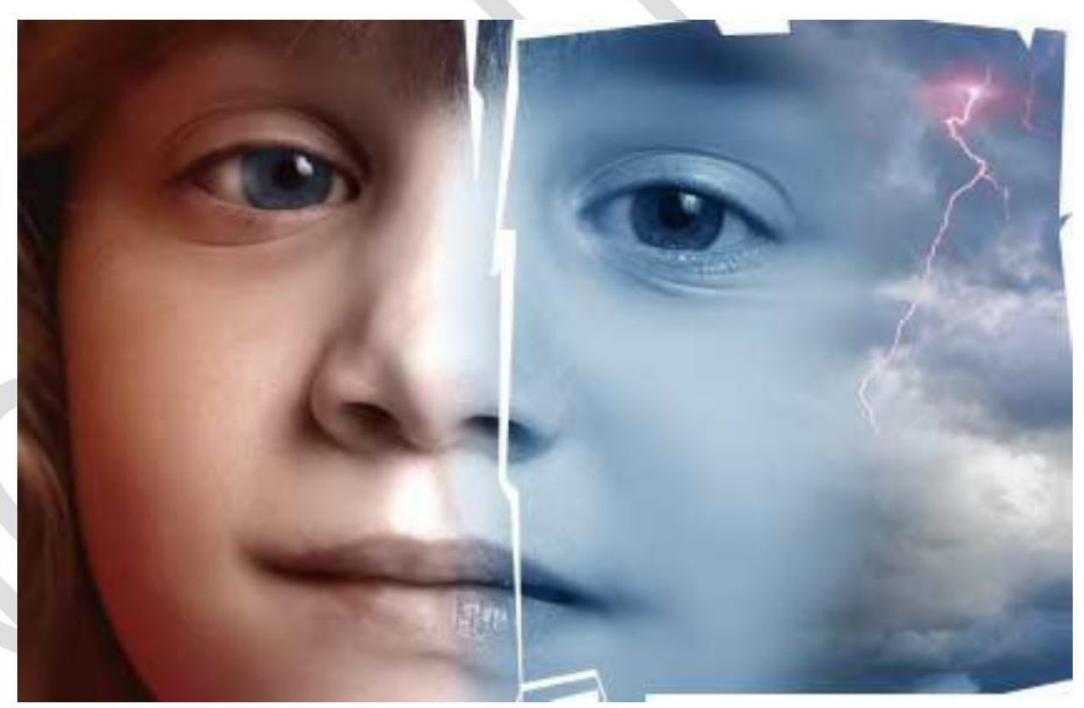

http://www.dailykos.com/story/2011/2/28/951224/- 
This clinical tool provides a model for assessment that can be used to diagnose bipolar disorder in the pediatric population. Data shows that the rate of diagnosis of the pediatric bipolar disorder is increasing (Littrell \& Lyons, 2010). Current literature demonstrates that there is evidence for biological and genetic changes that can be seen in the bipolar disorder patient, and the incorporation of the expanding field of science into diagnostic practices is warranted. Clinician survey data demonstrated inconsistent use of evidence-based assessment strategies. It is hoped that the use of this tool will help to improve the care and outcomes of child and adolescent patients everywhere!

Unless bipolar disorder is ruled out at an earlier phase in the process, it is recommended that phases I-III are completed prior to diagnosing bipolar disorder.

This tool is designed to be completed over several assessment sessions, and can be completed in specialty or primary care.

Littrell, J., \& Lyons, P. (2010). Pediatric bipolar disorder: Part I - is it related to classical bipolar. Children and Youth Services Review, 32, 945-964. doi:10.1016/j.childyouth.2010.03.020 
Phase I - Mood Assessment

Assessment for Mania or Hypomania - positive screening is indicated by 3 or more symptoms experienced for most of the day, nearly every day for 7 consecutive days or with hospitalization (mania), or 4 consecutive days (hypomania) (American Psychiatric Association, 2013).

Boldfaced criteria must be present to have a manic or hypomanic episode.

\begin{tabular}{|l|c|c|}
\hline Inflated self-esteem or grandiosity & YES & NO \\
\hline Decreased need for sleep & YES & NO \\
\hline Pressured speech & YES & NO \\
\hline Racing thoughts/Flight of ideas & YES & NO \\
\hline Distractibility & YES & NO \\
\hline Increased goal directed activity (social, work, sexual) & YES & NO \\
\hline Risk taking behavior/disinhibition & YES & NO \\
\hline Abnormally elevated, expansive, or irritable mood & YES & NO \\
\hline $\begin{array}{l}\text { Symptoms represent a distinct or uncharacteristic change } \\
\text { from the baseline mood }\end{array}$ & YES & NO \\
\hline
\end{tabular}

Assessment for Depression - 5 or more symptoms present during the same 2 -week period. One of the boldfaced symptoms must be present. A depressive episode will not necessarily be present in cases of Bipolar I disorder, but is required for a diagnosis of Bipolar II (American Psychiatric Association, 2013)

\begin{tabular}{|l|c|c|}
\hline $\begin{array}{l}\text { Depressed or irritable mood (increased hopelessness or } \\
\text { lability) }\end{array}$ & YES & NO \\
\hline Anhedonia & YES & NO \\
\hline Change in appetite (up or down) & YES & NO \\
\hline Sleep disturbance (increased or decreased) & YES & NO \\
\hline Psychomotor changes & YES & NO \\
\hline Fatigue/Decreased energy & YES & NO \\
\hline Feelings of worthlessness/guilt & YES & NO \\
\hline Trouble with concentration & YES & NO \\
\hline Frequent thoughts of death/Suicidal ideation & YES & NO \\
\hline
\end{tabular}

\begin{tabular}{|l|l|l|}
\hline $\begin{array}{l}\text { Mood disturbance is present in more than one setting (home, } \\
\text { school, sports) }\end{array}$ & YES & NO \\
\hline
\end{tabular} 
Other symptoms: The criteria above are what is required for diagnosis by DSM 5 standards, however other symptoms that should be noted, and raise suspicion of a mood disorder include: self-injurious behavior, eating disorder tendencies, symptoms of psychosis, and substance abuse.

Mood Tracking - Once assessment for pediatric bipolar disorder begins, have the patient and or their family begin to mood journal. Further assessment is warranted if mood instability is demonstrated by frequent changes in mood state, or sleep disturbance is apparent. Tracking should be retrospective to the extent possible, and ongoing to help identify patterns and cycles. This can be completed via pen and paper, or by using a smartphone application; there are several available.

$$
\begin{array}{|l|l|l|}
\hline \text { Mood tracking warrants continued assessment } & \text { YES } & \text { NO } \\
\hline
\end{array}
$$

American Psychiatric Association. (2013). Diagnostic and Statistical Manual of Mental Disorders (5th ed.). Arlington, VA: American Psychiatric Association.

\section{Phase II - Scales}

Validated and reliable rating scales should be used at this time, if pediatric bipolar disorder is still suspected. Many tools are available. The FIRM (Algorta, et al., 2013) and CMRS-P (Pavuluri, Henry, Devineni, Carbray, \& Birmaher, 2006) are offered here. Both should be completed by parents or guardians. Completion of the CMRS-P by collateral informants (teachers, coaches, etc...) could be useful as well. Scores of 20 or greater on the CMRS-P warrant further assessment (Pavuluri, et al., 2006). If the FIRM is not used clinically, obtaining a thorough, multi-generational family history of mental illness, substance abuse, and sleep disturbances is imperative.

CMRS-P assesses the symptoms of the patient, while the FIRM helps with the understanding of the family history.

Permission for use in academic or research contexts is available for the FIRM, and the CMRS-P is available for download on the internet.

(http://www.dbsalliance.org/pdfs/ChildManiaSurvey.pdf)

Algorta, G. P., Youngstrom, E. A., Phelps, J., Jenkins, M. M., Youngstrom, J. K., \& Findling, R. L. (2013). An inexpensive family index of risk for mood issues improves identification of pediatric bipolar disorder. Psychological Assessment, 25(1), 12-22.

Pavuluri, M. N., Henry, D. B., Devineni, B., Carbray, J. A., \& Birmaher, B. (2006). Child mania rating scale: Development, reliability, and validity. Journal of the American Academy of Child \& Adolescent Psychiatry, 45(5), 550-560. 


\section{FIRM}

Family Index of Risk for Mood

FIRM

Items

Please indicate whether any of your (blood) relatives have had any of these concerns:

\begin{tabular}{|c|c|c|c|c|c|}
\hline Suicide & $\square$ & $\square$ & $\square$ & $\square$ & $\square$ \\
\hline Alcohol/Drug Problems & $\square$ & $\square$ & $\square$ & $\square$ & $\square$ \\
\hline Depression Problems & $\square$ & $\square$ & $\square$ & $\square$ & $\square$ \\
\hline Manic or Bipolar & $\square$ & $\square$ & $\square$ & $\square$ & $\square$ \\
\hline
\end{tabular}

Has a health professional ever told you that you have manic-depressive illness or bipolar disorder? 


\section{CMRS-P}

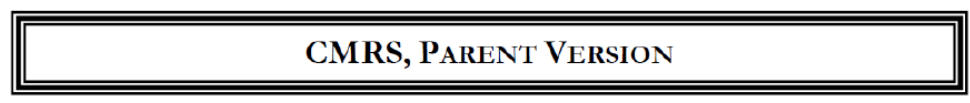

$\begin{array}{ll}\text { Child's name } & \begin{array}{l}\text { Date of Birth } \\ (\mathrm{mm} / \mathrm{dd} / \mathrm{yy})\end{array}\end{array}$

INSTRUCTIONS

The following questions concern your child's mood and behavior in the past month. Please place a check mark or an ' $\mathrm{x}$ ' in a box for each item. Please consider it a problem if it is causing trouble and is beyond what is normal for your child's age. Otherwise, check 'rare or never' if the behavior is not causing trouble.

Does your child. . .

$\begin{array}{lll}\text { NEVER/ SOMETIMES OFTEN } & \text { VERY } \\ \text { RARELY } & \text { OFTEN }\end{array}$

1. Have periods of feeling super happy for hours or days at a time, extremely wound up and excited, such as feeling "on top of the world"

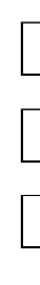

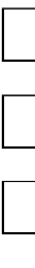
powers that are unusual, and may try to act upon them, which causes trouble

5. Need less sleep than usual; yet does not feel tired the next day

6. Have periods of too much energy

7. Have periods when she or he talks too much or too loud or talks a mile-a-minute

8. Have periods of racing thoughts that his or her mind cannot slow down, and it seems that your child's mouth cannot keep up with his or her mind

9. Talk so fast that he or she jumps from topic to topic

10. Rush around doing things nonstop

11. Have trouble staying on track and is easily drawn to what is happening around him or her

12. Do many more things than usual, or is unusually productive or highly creative
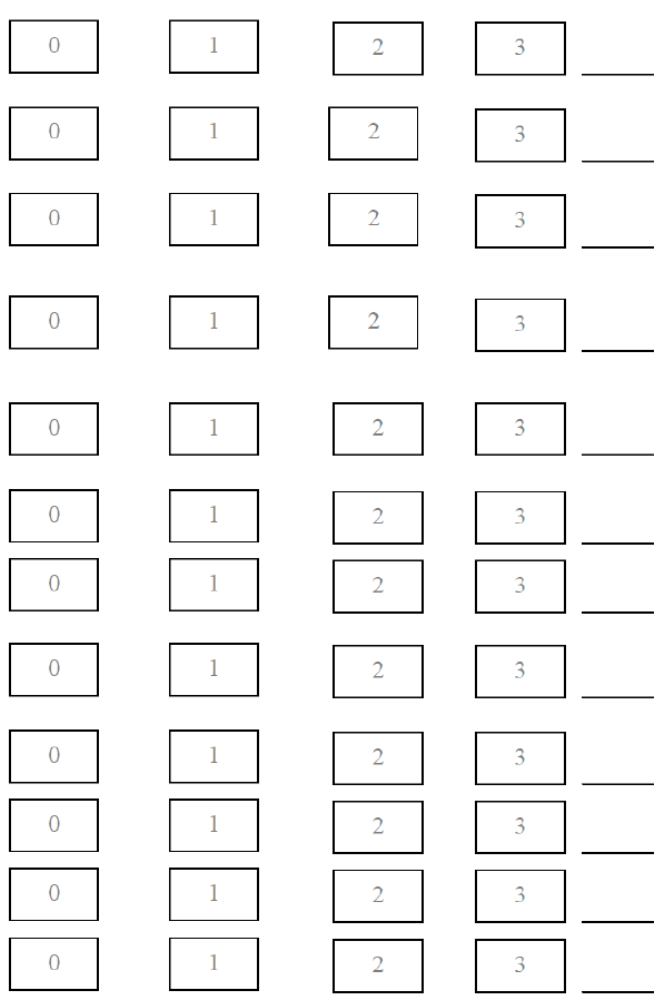

13. Behave in a sexually inappropriate way (e.g., talks dirty, exposing, playing with private parts, masturbating, making sex phone calls, humping on masturbating, making sex phone calls, humping on
dogs, playing sex games, touches others sexually)

14. Go and talk to strangers inappropriately, is more socially outgoing than usual
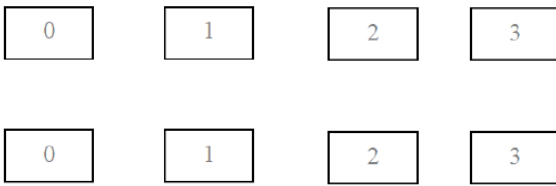
Does your child. . .

15. Do things that are unusual for him or her that are foolish or risky (e.g., jumping off heights, orderin $\mathrm{CDs}$ with your credit cards, giving things away)

16. Have rage attacks, intense and prolonged temper tantrums

17. Crack jokes or pun more than usual, laugh loud, or act silly in a way that is out of the ordinary

18. Experience rapid mood swings

19. Have any suspicious or strange thoughts

20. Hear voices that nobody else can hear

21. See things that nobody else can see
NEVER SOMETIMES OFteN VERY

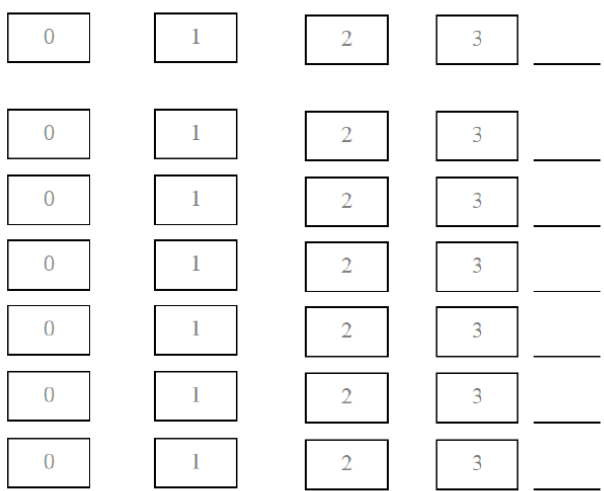

TOTAI SCORE

\section{Phase III - Laboratory Studies}

If pediatric bipolar disorder has not been ruled out by Phases I and II, further evaluation should be completed. Laboratory studies are recommended to rule out any underlying medical comorbidities that may cloud the clinical presentation; these would also allow for baseline levels to be obtained should pharmacologic management commence in the future.

Though the laboratory tests ordered should be based upon the assessment of the clinician, some routine recommendations to consider are: $\mathrm{CBC}$ with diff, $\mathrm{CMP}$, lipid panel, $\mathrm{Hgb} \mathrm{A} 1 \mathrm{C}$, and TSH. Other tests that may be warranted based on the individual patient presentation might include: UDS, urine HCG, Vitamin D, and MTHFR status.

\begin{tabular}{|l|c|c|c|}
\hline Complete Blood Count w/differential & WNL & ABN & NA \\
\hline Comprehensive Metabolic Panel & WNL & ABN & NA \\
\hline Lipid Panel & WNL & ABN & NA \\
\hline Hemoglobin A1C & WNL & ABN & NA \\
\hline Thyroid Stimulating Hormone (T3, T4 if indicated) & WNL & ABN & NA \\
\hline Urine Drug Screen & WNL & ABN & NA \\
\hline
\end{tabular}




\begin{tabular}{|l|l|l|l|}
\hline Urine HCG & WNL & ABN & NA \\
\hline Vitamin D & WNL & ABN & NA \\
\hline MTHFR Status & WNL & ABN & NA \\
\hline
\end{tabular}

Bipolar disorder may be able to be ruled in or out at this point. If the clinical picture remains unclear, further testing is recommended, proceed the next phase.

\section{Phase IV - MRI Scanning}

MRI studies of the brain may be considered to assess for neurobiologic changes, particularly changes in gray matter volume (GMV) (James, et al., 2011).

\section{\begin{tabular}{|l|l|l|} 
MRI reflective of changes in GMV & YES & NO
\end{tabular}}

James, A., Hough, M., James, S., Burge, L., Winmill, L., Nijhawan, S.,...Zarei, M. (2011). Structural brain and neuropsychometric changes associated with pediatric bipolar disorder with psychosis. Bipolar Disorders, 13, 16-27. doi:10.1111/j.1399-

5618.2011.00891.x 
APPENDIX E: PERMISSION FOR USE 
Appendix E - Permission for Use

Amanda Horrocks

Mar 26 (5 days ago)

to mpavuluri -

Good evening, Dr. Pavuluri,

I am a doctoral student, and am creating a clinical tool for the assessment and diagnosis of pediatric bipolar disorder as a part of my program. I found the CMRS-P available as a freely accessed PDF on the internet (http://www.dbsalliance.org/pdfs/ChildManiaSurvey.pdf), and wanted to ensure that it was available to be used for academic purposes without separate permissions, prior to doing so.

If not, I wanted to seek your permission/boundaries for using the CMRS-P, in an academic context, as a part of an evidence-based assessment process that I am creating.

Thank you for your time.

Kind Regards,

Amanda Horrocks, NP, DNP(c)

Pavuluri, Mani N.

Mar 27 (4 days ago)

to me -

Oh please feel free to use. It is yours! And for all of us to use!

Mani Pavuluri, MD PhD 